
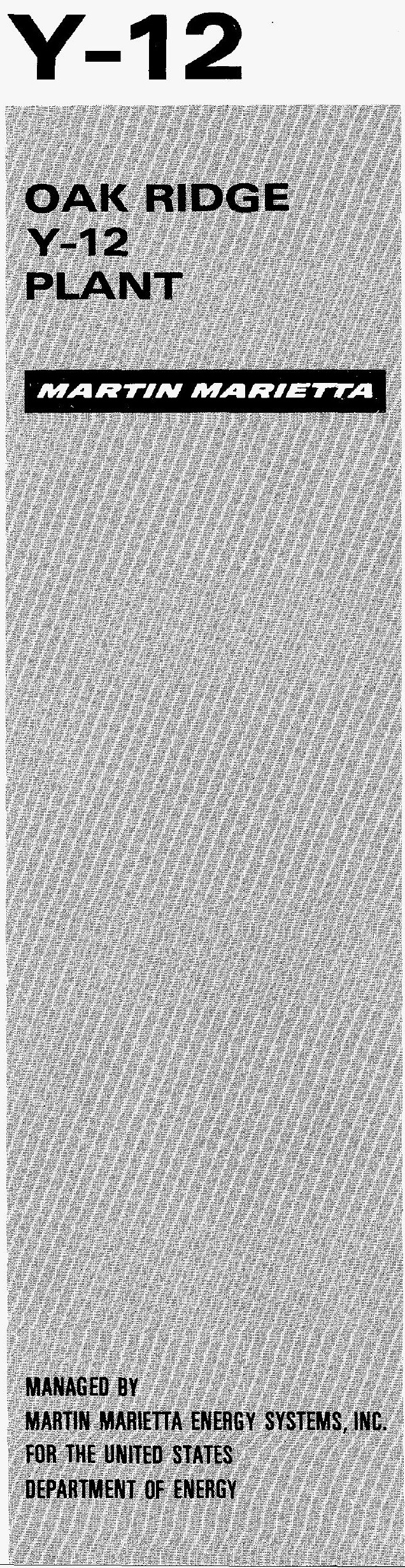

E. L. Bird

T. L. Clift

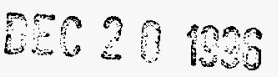

June 1996

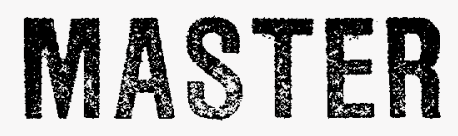




\section{DISCLAIMER}

This report was prepared as an account of work sponsored by an agency of the United States Government. Neither the United States Government nor any agency thereof, nor any of their employees, makes any warranty, express or implied, or assumes any legal liability or responsibility for the accuracy, completeness, or usefulness of any information, apparatus, product, or process disclosed, or represents that its use would not infringe privately owned rights. Reference herein to any specific commercial product, process, or service by trade name, trademark, manufacturer, or otherwise, does not necessarily constitute or imply its endorsement, recommendation, or favoring by the United States Government or any agency thereof. The views and opinions of authors expressed herein do not necessarily state or reflect those of the United States Government or any agency thereof. 


\title{
METALLURGICAL EXAMINATION OF GUN BARREL SCREWS
}

\author{
E. L. Bird
}

Materials Engineering Department

T. L. Clift

Instrumentation and Characterization Department

Y-12 Development Division

June 1996

\author{
Prepared by the \\ Oak Ridge Y-12 Plant
}

P. O. Box 2009, Oak Ridge, Tennessee 37831-8169

managed by

LOCKHEED MARTIN ENERGY SYSTEMS, INC.

for the

U. S. DEPARTMENT OF ENERGY

under contract DE-AC05-84OR21400 


\section{DISCLAIMIER}

Portions of this document may be illegible in electronic image products. Images are produced from the best available original document. 


\section{CONTENTS}

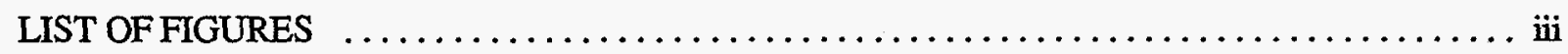

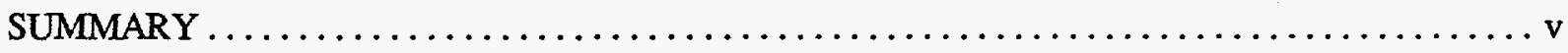

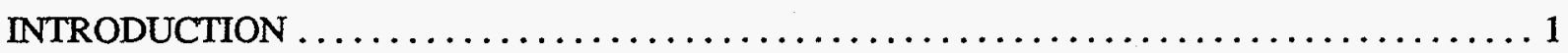

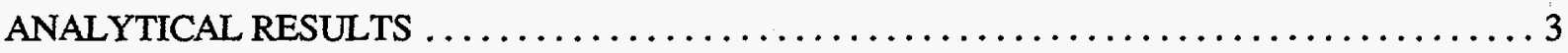

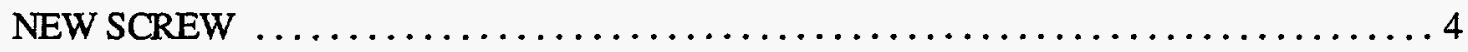

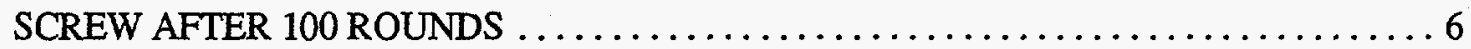

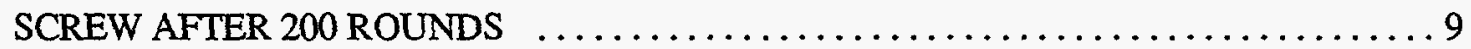

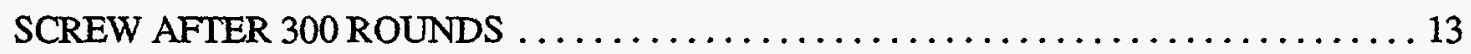

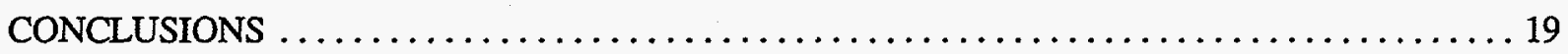

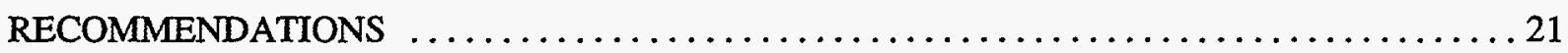

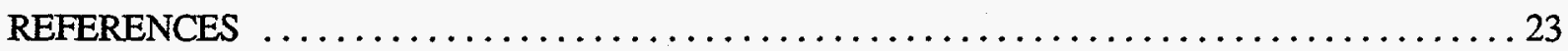





\section{FIGURES}

Screw used to prevent live round from entering the firing

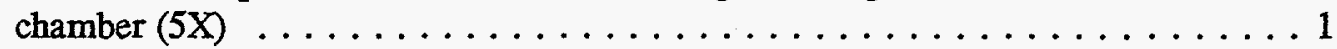

Scanning electron microscopy images of new, unfired screws

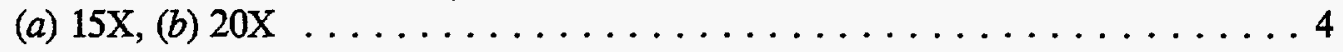

3(a) Polished cross section of a new screw $(30 \mathrm{X}) \ldots \ldots \ldots \ldots$

3(b) Etched microstructure showing tempered martensite (Etch: 5\% Nital, 200X) . . . 5

4(a) Scanning electron microscopy image of a screw after 100 rounds $(15 \mathrm{X}) \ldots \ldots$

4(b) Gunshot/powder residue on the surface of a 100 -round screw $(300 x) \ldots \ldots$

5(a) Polished cross section of a screw after 100 rounds $(30 \mathrm{X}) \ldots \ldots \ldots \ldots$

5(b) Magnified view of top portion of Fig. 5(a) showing the presence of shallow

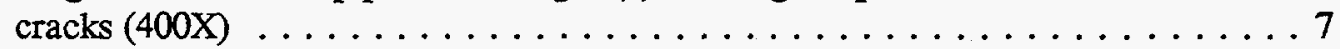

5(c) Magnified view of the top left corner of Fig. 5(a) showing shallow cracks and areas of degradation $(400 \mathrm{X}) \ldots \ldots \ldots \ldots \ldots \ldots$

6(a) Etched microstructure of a screw after 100 rounds (Etch: $2 \%$ Nital, $30 \mathrm{X}$ ) $\ldots \ldots 8$

6(b) $\quad$ Magnified view of top left corner of Fig. $6(\mathrm{a})(150 \mathrm{X}) \ldots \ldots \ldots$

7 (a) $\quad$ Residue on a screw after 200 rounds $(30 \mathrm{X}) \ldots \ldots \ldots$

7(b) "Mud cracks" in the residue deposited on a 200 -round screw $(1000 \mathrm{X}) \ldots . \ldots$

8(a) Polished cross section of a screw after 200 rounds. Note the increase in the number of cracks along the top surface. $(30 \mathrm{X}) \ldots \ldots \ldots \ldots$

8(b) Magnification increased for a closer look at the degree of cracking in the left upper portion of Fig. $8($ a) $(400 x) \ldots \ldots \ldots \ldots \ldots \ldots \ldots \ldots$

9(a) Etched microstructure of a screw after 200 fired rounds. Note the "white layer" at the top left portion of the screw. $(30 \mathrm{X}) \ldots \ldots \ldots \ldots \ldots$

9(b) A closer view of the white layer on the screw from 200 fired

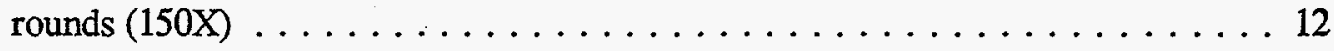


11(a) Scanning electron microscopy image of a screw after 300 rounds. Note the enclosed box depicting the region of heavy residue and cracking. (20X) . . . 13

11(b) Scanning electron microscopy image of the enhanced area from Fig. 11(a) showing cracking at higher magnification $(100 \mathrm{X}) \ldots \ldots \ldots \ldots . \ldots \ldots$

12(a) Polished cross section of a screw after 300 rounds. Note the severity of the cracking and wear, which is predominant on the left side of the screw. $(30 \mathrm{X})$

12(b) Magnified view of Fig. 11(a), upper left corner, showing the depth of the crack (approximately 0.017 in.) and deformed metal at the crack origin $(100 \mathrm{X})$

13(a) Etched view of a screw after 300 rounds. Note the white zone or band across the screw in a plane slightly above the threaded plane and the difference in the appearance of the microstructure above and below this band. $(30 \mathrm{X}) \ldots \ldots \ldots 15$

13(b) Magnified view of the region above the top, left thread shown in the bottom left portion of Fig. 12(a). The differences in microstructure are more evident. (150X)

Profiles of Knoop hardness tests at a 500-g load for $15 \mathrm{~s}$. (a) and

(b) 300-round screws, (c) new screw (30X) $16-17$ 


\section{SUMMARY}

The authors conducted a metallurgical examination of screws to determine the extent of degradation that had occurred after a series of firings. These screws prevent live rounds of ammunition from being loaded into the firing chamber. One of the primary concerns is that if the screw tip fails to perform its intended purpose and a live round is accidentally loaded into the chamber, a live round could be fired. Another concern is that if the blunt end of the screw begins to degrade by cracking, pieces or fragments could become small projectiles during a firing exercise.

Initially, the authors evaluated two screws that had been exposed to the firing of 300 rounds. Later, they included in their investigation screws representing 100 and 200 rounds of firing. The authors performed scanning electron microscopy, metallography, X-ray analysis, and microhardness testing to complete the examination of the screws before comparing the results with a new screw that had never been fired.

All of the screws used in firing 100 rounds or more exhibited some degree of degradation, which progressively worsened as the number of rounds fired increased. After 100 rounds, the tip experienced minimal wear, a small amount of gun powder residue covered the surface, and slight microcracking occurred in the flat section of the screw tip. Screws that had experienced the firing of 200 rounds revealed more evidence of wear with more extensive cracking, additional gun powder residue, and structural transformation in a region near the surface of heaviest wear. Screws that had been exposed to the firing of 300 rounds showed the most wear, residue, cracking, and significant changes in the microstructure in the blunt tip or unthreaded region. Microhardness testing of some of these regions revealed significant changes in the hardness of the material.

The presence of cracks in these screws after 100 fired rounds is a serious concern that warrants the discontinued use of these screws. The performance of the screw could be improved by selecting a different alloy that is more resistant to thermal and chemical degradation. 


\section{INTRODUCTION}

Small screws, such as the one shown in Fig. 1, are used to prevent live rounds of ammunition from entering the firing chamber when certain firing exercises are performed. The blunt tip of the screw, including one or two threads, lies inside the barrel and is exposed to the explosive reaction and stresses of firing a blank round. Blank rounds do not contain a live projectile. The metallurgical integrity of these screws must be maintained to ensure that the screws function as intended and do not fracture or fragment. The authors examined several screws that had been exposed to the firing of 100,200 , and 300 rounds to determine if any degradation had occurred. Of primary concern was any indication of brittleness, wear, or cracking that might indicate a degradation in the life expectancy of the component.

A typical scenario suggests that during the firing of each round, the screw is subjected to high temperatures, a pressure burst, and gun powder residue. Multiple-round firing, which is typical in firing exercises, creates cyclic stresses on the portion of the screw inside the chamber. Discussions with Security Force personnel indicate that gun powder consists of an explosive mixture of nitroglycerine and nitrocellulose. Primers typically consist of mixtures of lead, antimony, and barium.

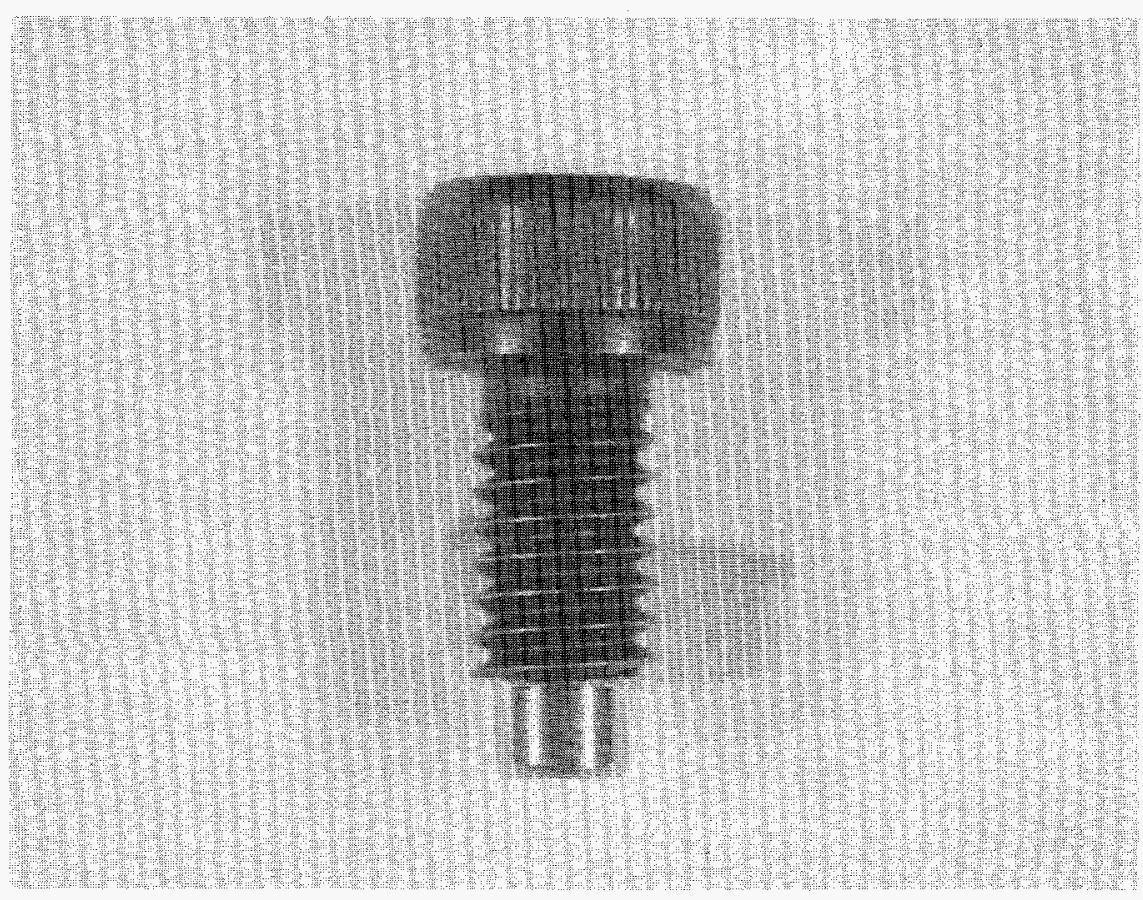

Fig. 1. Screw used to prevent a live round of ammunition from entering the firing chamber (5X). 


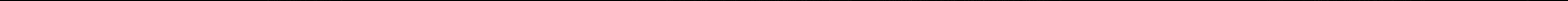




\section{ANALYTICAL RESULTS}

The authors visually and dimensionally inspected the screws before they examined them in the scanning electron microscope (SEM). Then they cut, mounted, and polished each sample for optical metallographic evaluation. They used Nital as the etchant to bring out the microstructural features of the alloy. The Y-12 Plant Laboratory also tested a new screw to determine its actual chemical composition; Table 1 shows the results of their test.

Table 1. Chemical composition of new screw ${ }^{a, b}$

\begin{tabular}{|c|c|c|c|c|c|}
\hline Element & $\begin{array}{l}\text { Weight } \\
\text { (ppm) }\end{array}$ & Element & $\begin{array}{l}\text { Weight } \\
\text { (ppm) }\end{array}$ & Element & $\begin{array}{l}\text { Weight } \\
\text { (ppm) }\end{array}$ \\
\hline $4 \mathrm{Be}$ & $<0.1$ & $33 \mathrm{As}$ & 5.0 & $62 \mathrm{Sm}$ & $<1.0$ \\
\hline $5 \mathrm{~B}$ & 0.2 & $34 \mathrm{Se}$ & $<18.0$ & $63 \mathrm{Eu}$ & $<0.5$ \\
\hline $6 \mathrm{C}$ & $3,300.0$ & $35 \mathrm{Br}$ & $<50.0$ & $64 \mathrm{Gd}$ & $<1.0$ \\
\hline $9 \mathrm{~F}$ & $<120.0$ & $37 \mathrm{Rb}$ & $<0.2$ & $65 \mathrm{~Tb}$ & $<0.3$ \\
\hline $11 \mathrm{Na}$ & $<0.1$ & $38 \mathrm{Sr}$ & $<0.2$ & 66 Dy & $<1.0$ \\
\hline $12 \mathrm{Mg}$ & $<0.1$ & $39 \mathrm{Y}$ & $<0.2$ & $67 \mathrm{Ho}$ & $<0.3$ \\
\hline $13 \mathrm{Al}$ & 400.0 & $40 \mathrm{Zr}$ & 1.0 & $68 \mathrm{Er}$ & $<0.9$ \\
\hline $14 \mathrm{Si}$ & $1,900.0$ & $41 \mathrm{Nb}$ & 0.4 & $69 \mathrm{Tm}$ & $<0.3$ \\
\hline $15 \mathrm{P}$ & 130.0 & $42 \mathrm{Mo}$ & $2,400.0$ & $70 \mathrm{Yb}$ & $<1.0$ \\
\hline $16 \mathrm{~S}$ & 110.0 & $44 \mathrm{Ru}$ & $<1.0$ & $71 \mathrm{Lu}$ & $<0.3$ \\
\hline $17 \mathrm{C} 1$ & 250.0 & $45 \mathrm{Rh}$ & $<0.4$ & $72 \mathrm{Hf}$ & $<1.0$ \\
\hline $19 \mathrm{~K}$ & $<0.1$ & $46 \mathrm{Pd}$ & 3.0 & $73 \mathrm{Ta}$ & $<0.5$ \\
\hline $20 \mathrm{Ca}$ & $<4.0$ & $47 \mathrm{Ag}$ & $<1.0$ & $74 \mathrm{~W}$ & $<2.0$ \\
\hline $21 \mathrm{Sc}$ & $<0.1$ & $48 \mathrm{Cd}$ & $<1.0$ & $75 \mathrm{Re}$ & $<0.8$ \\
\hline $22 \mathrm{Ti}$ & 19.0 & 49 In & $<0.2$ & 76 Os & $<3.0$ \\
\hline $23 \mathrm{~V}$ & 15.0 & $50 \mathrm{Sn}$ & $<1.0$ & $77 \mathrm{Ir}$ & $<3.0$ \\
\hline $24 \mathrm{Cr}$ & 160.0 & $51 \mathrm{Sb}$ & 1.0 & $78 \mathrm{Pt}$ & $<9.0$ \\
\hline $25 \mathrm{Mn}$ & $6,800.0$ & $52 \mathrm{Te}$ & $<4.0$ & $79 \mathrm{Au}$ & $<5.0$ \\
\hline $26 \mathrm{Fe}$ & $984,000.0$ & $53 I$ & $<10.0$ & $80 \mathrm{Hg}$ & $<4.0$ \\
\hline $27 \mathrm{Co}$ & 33.0 & $55 \mathrm{Cs}$ & $<0.2$ & $81 \mathrm{~T} 1$ & $<0.6$ \\
\hline $28 \mathrm{Ni}$ & 150.0 & $56 \mathrm{Ba}$ & $<0.3$ & $82 \mathrm{~Pb}$ & $<1.0$ \\
\hline $29 \mathrm{Cu}$ & 140.0 & $57 \mathrm{La}$ & $<0.3$ & $83 \mathrm{Bi}$ & $<0.6$ \\
\hline $30 \mathrm{Zn}$ & 1.0 & $58 \mathrm{Ce}$ & $<0.3$ & $90 \mathrm{Th}$ & $<0.5$ \\
\hline $31 \mathrm{Ga}$ & 3.0 & $59 \mathrm{Pr}$ & $<0.3$ & $92 \mathrm{U}$ & $<0.5$ \\
\hline $32 \mathrm{Ge}$ & 1.0 & $60 \mathrm{Nd}$ & $<1.0$ & & \\
\hline
\end{tabular}

Total impurities detected $=1674.800 \mathrm{ppm}($ LESS THANS AT FULL VALUE)

${ }^{a}$ Total impurities do not inclue weight $\mathrm{ppm}$ values $=$ or $>1000$ weight ppm or items denoted as matrix.

${ }^{b}$ By difference $=99.858 \%$ (less thans ignored)

Number of elements reported $=74$ 


\section{NEW SCREW}

Figure 2 shows SEM photographs of the new or unfired screw for reference. Figure 3(a) is a cross section of the new screw, and Fig. 3(b) shows the microstructure near the first thread of the same screw at a higher magnification. Note the absence of any cracks in Fig. 3(a) and the presence of a tempered martensitic microstructure in Fig. 3(b).

(a)
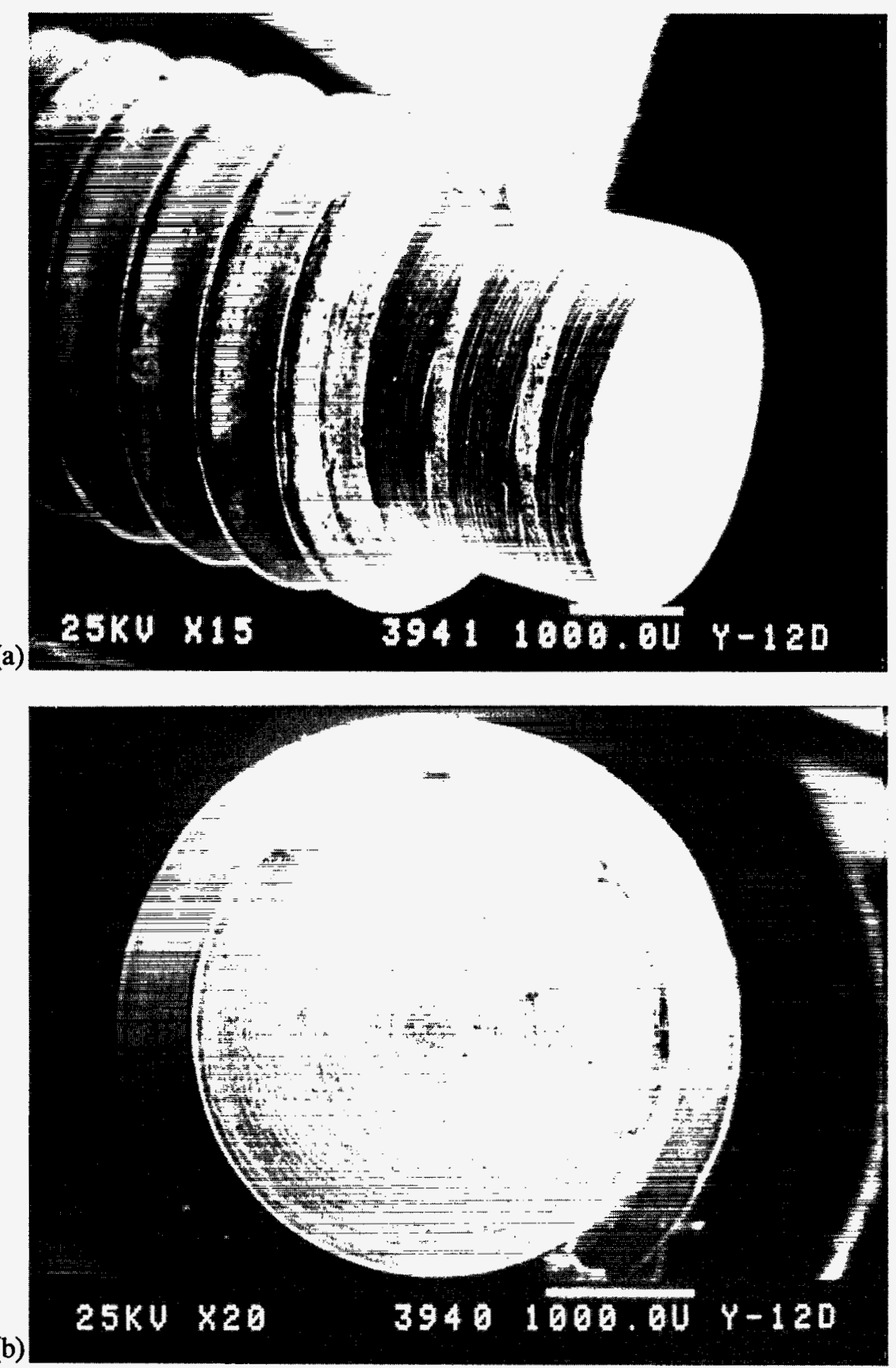

Fig. 2. Scanning electron microscopy images of new, unfired screws (a) $15 \mathrm{X}$, (b) $20 \mathrm{X}$. 


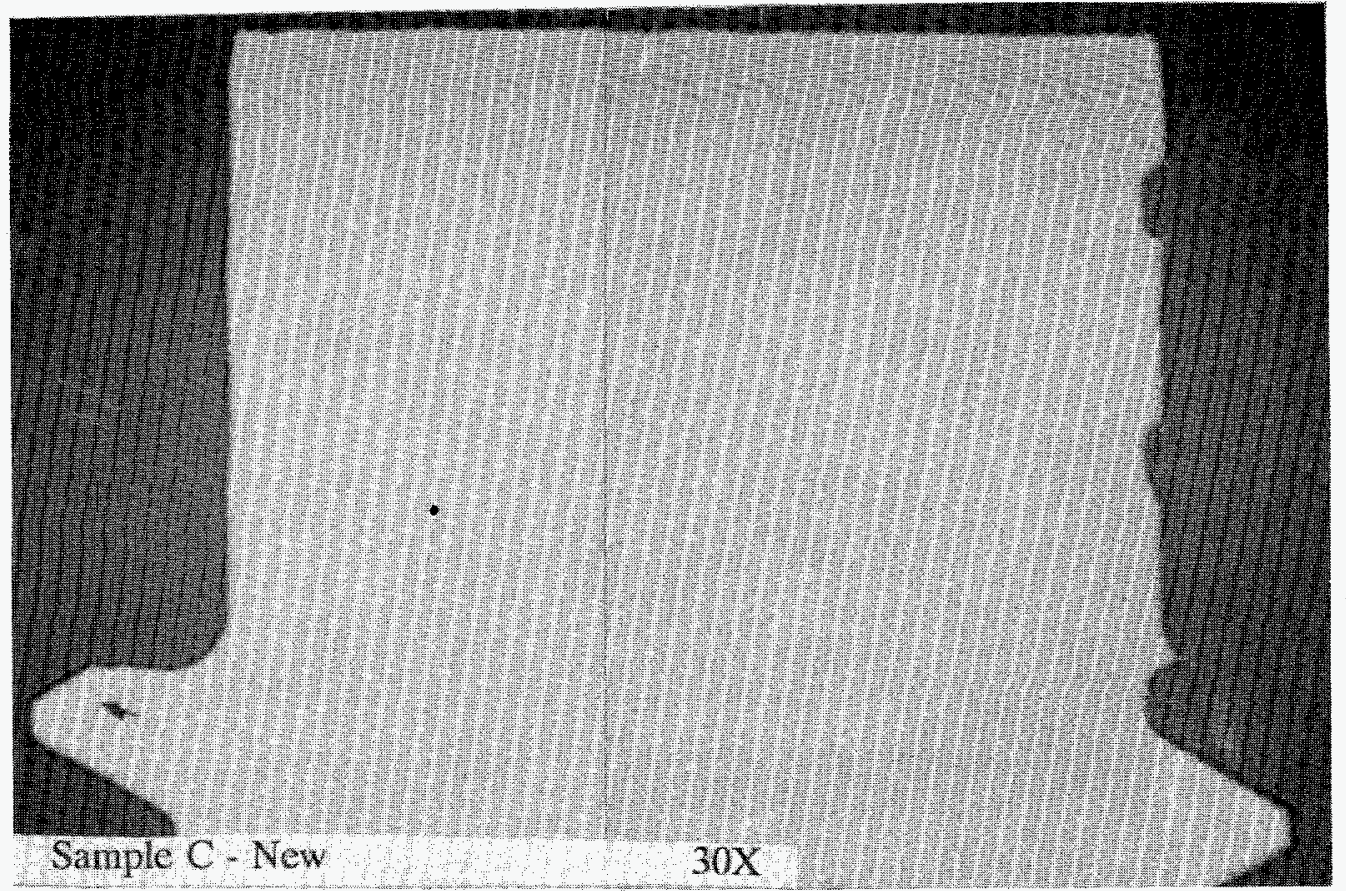

Fig. 3(a). Polished cross section of a new screw (30X).

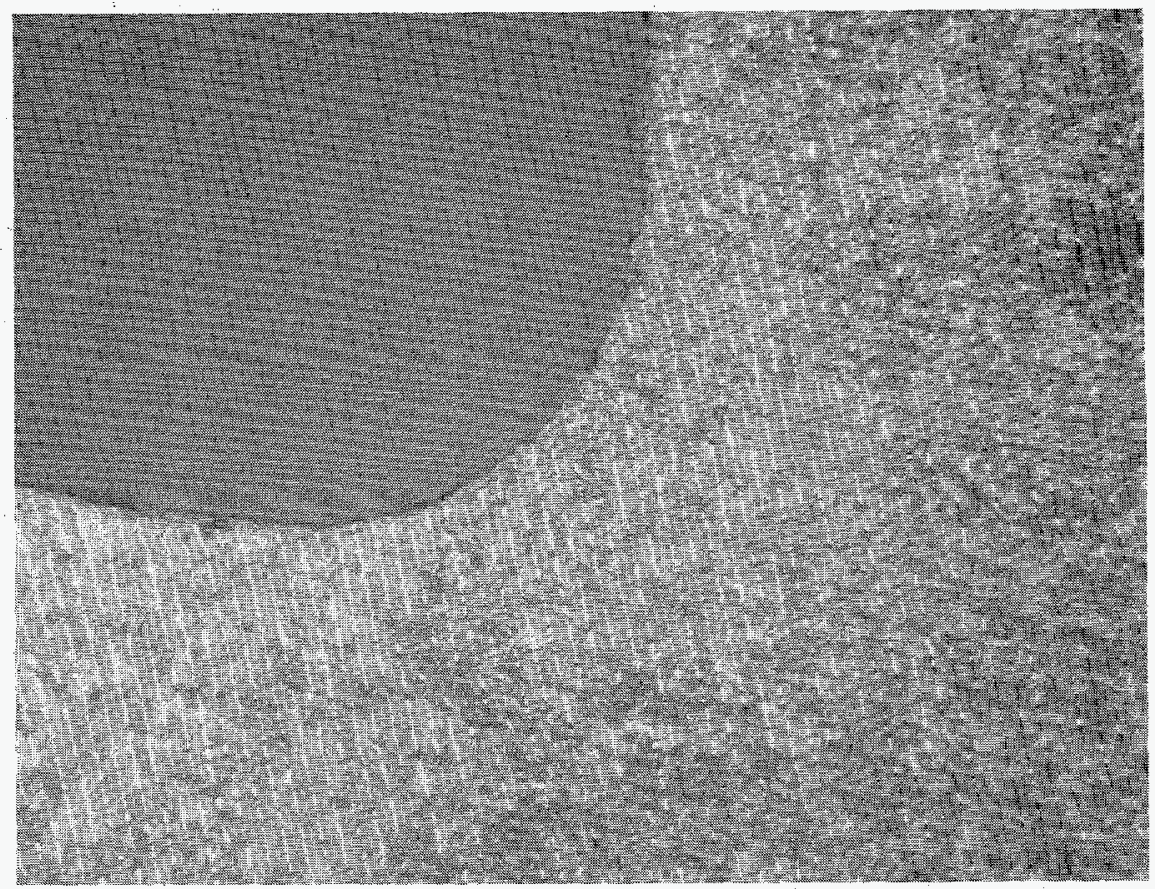

Fig. 3(b). Etched microstructure showing tempered martensite (Etch: 5\% Nital, 200X). 


\section{SCREW AFTER 100 ROUNDS}

After being exposed to 100 fired rounds, the screw looks like the SEM pictures in Fig. 4. Some of the powder residue is evident in Fig. 4(b). Figure 5 shows cross sections of the screw that was polished but not etched, and one can see that small cracks are beginning to form in the upper region of the screw. The etched version of the microstructure (Fig. 6) reveals predominantly tempered martensite with a small region in the top, left corner exhibiting slight transformation.

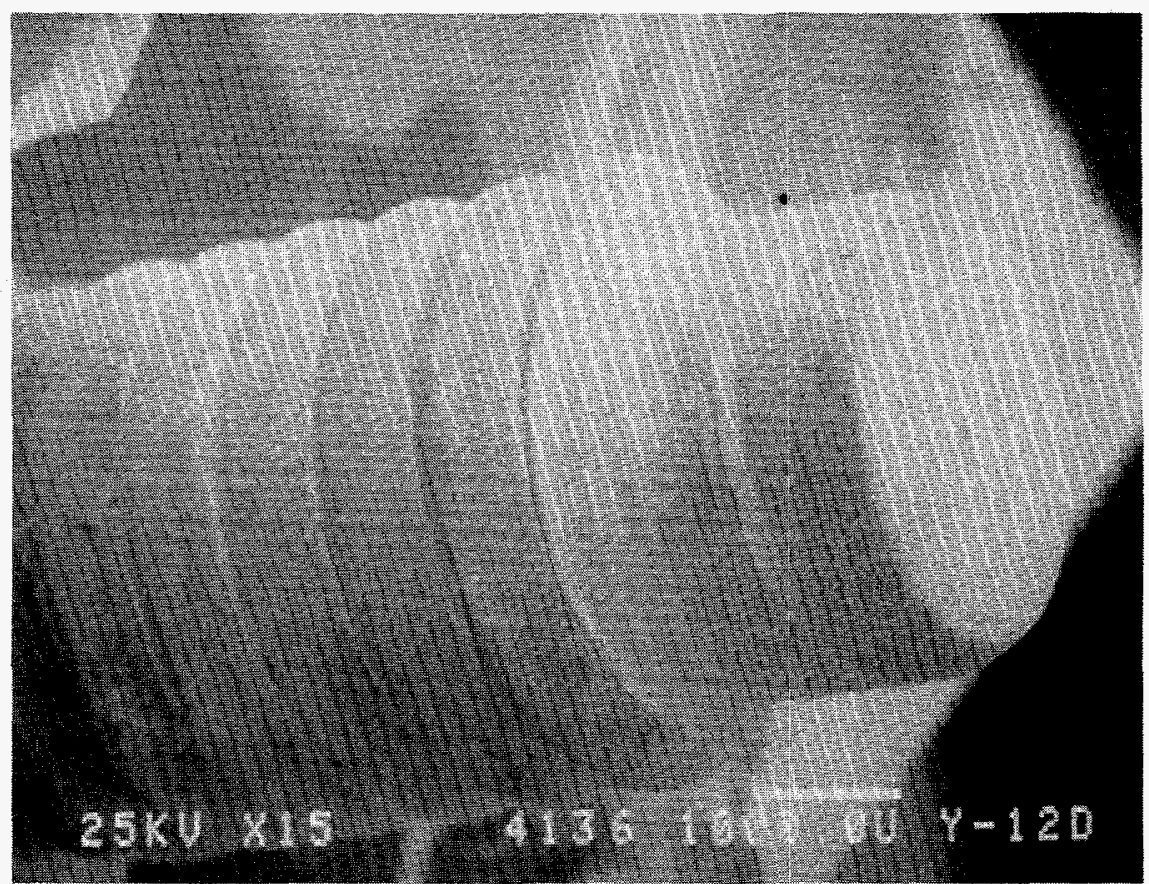

Fig. 4(a). Scanning electron microscopy image of a screw after 100 rounds (15X).

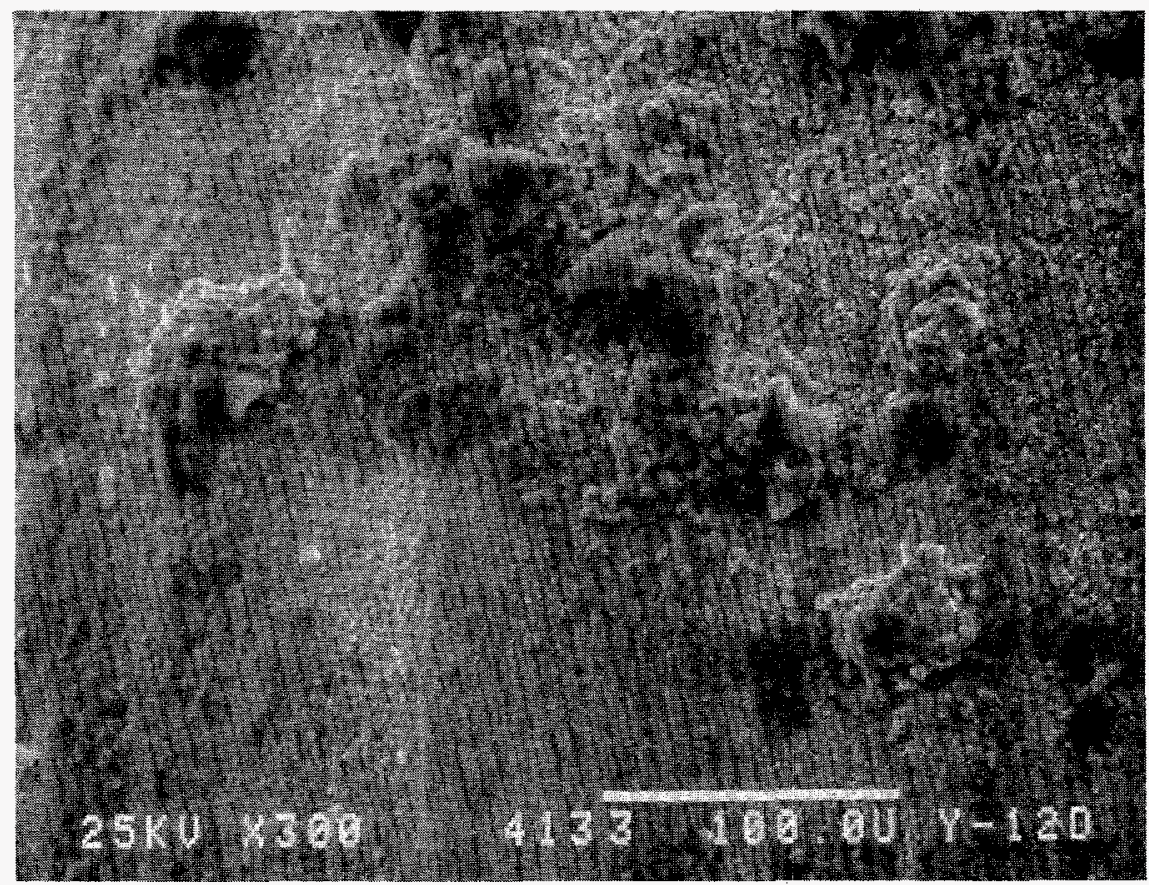

Fig. 4(b). Gunshot/powder residue on the surface of a 100-round screw (300X). 
(a)

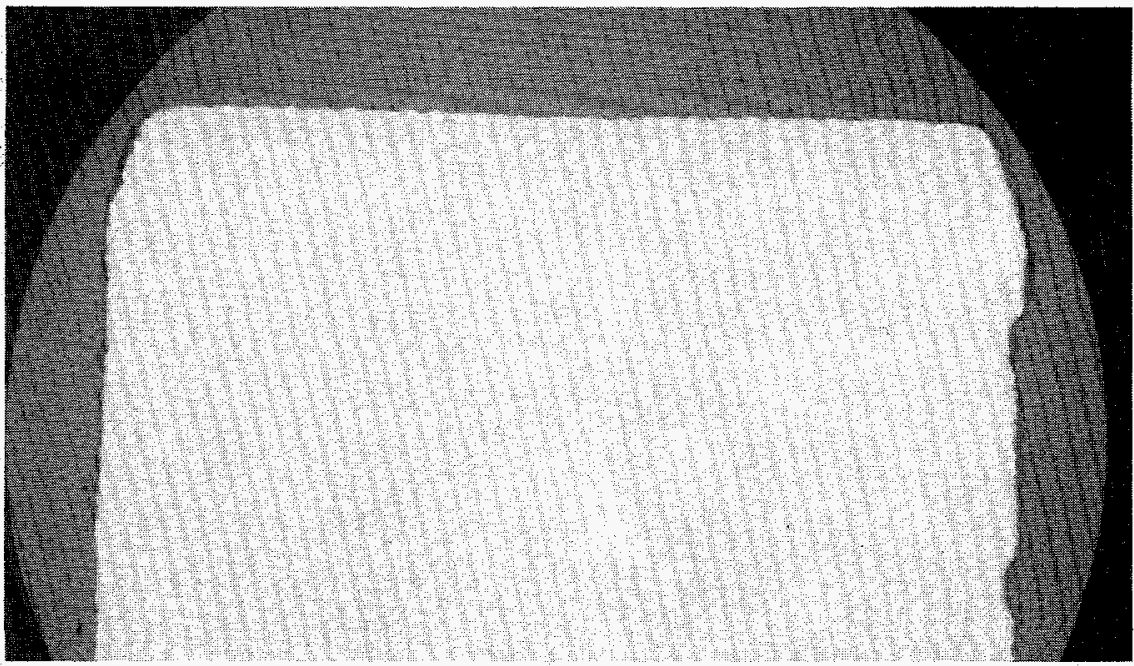

Fig. 5(a). Polished cross section of a screw after 100 rounds (30X).

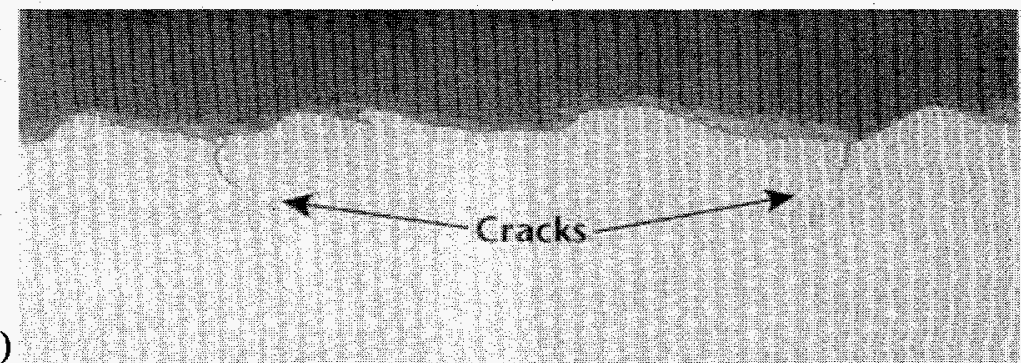

Fig. 5(b). Magnified view of top portion of Fig. 5(a) showing the presence of shallow cracks $(400 \mathrm{X})$.

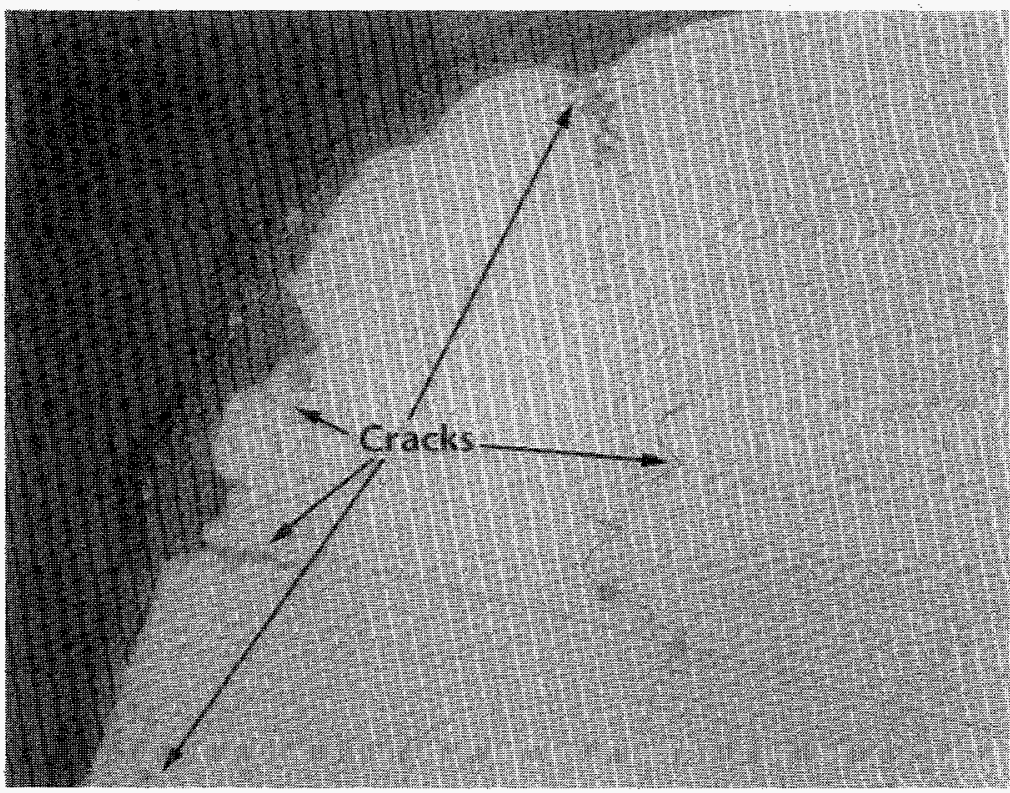

Fig. 5(c). Magnified view of the top left corner of

Fig. 5(a) showing shallow cracks and areas of degradation $\quad(400 X)$. 


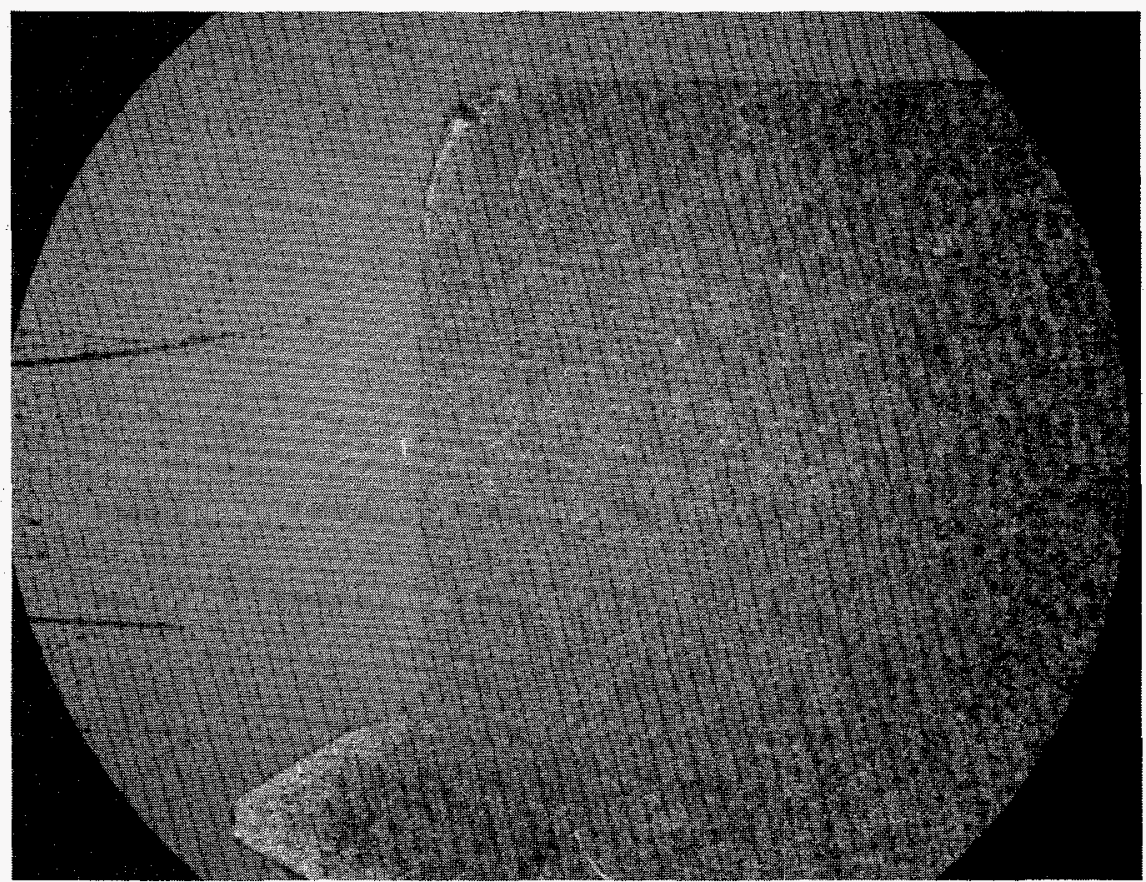

Fig. 6(a). Etched microstructure of a screw after 100 rounds (Etch: 2\% Nital, 30X).

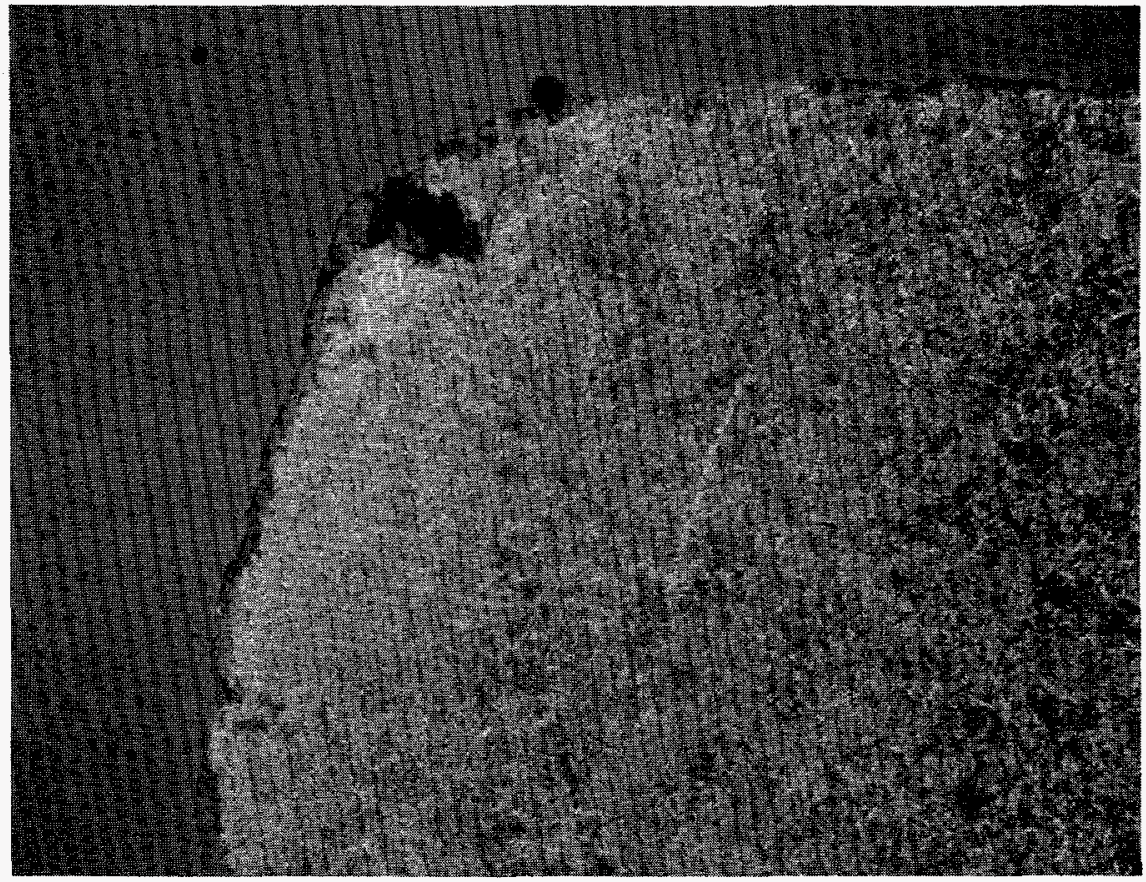

Fig. 6(b). Magnified view of top left corner of Fig. 6(a) (150X). 


\section{SCREW AFTER 200 ROUNDS}

Figure 7 shows the screw that had been used in the firing of 200 rounds; the presence of cracking and wear is more pronounced. Figure 8 shows a polished, cross-sectional region that reveals

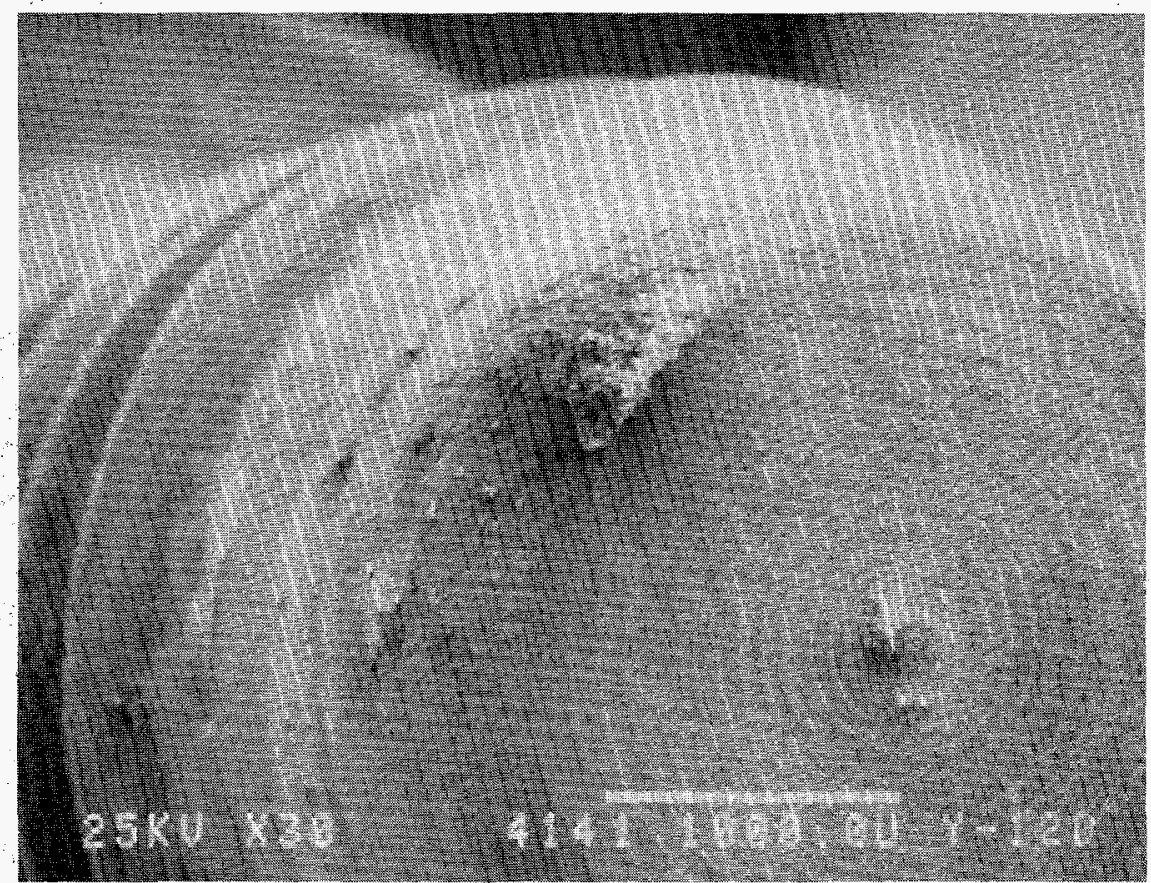

Fig. 7(a). Residue on a screw after 200 rounds (30X).

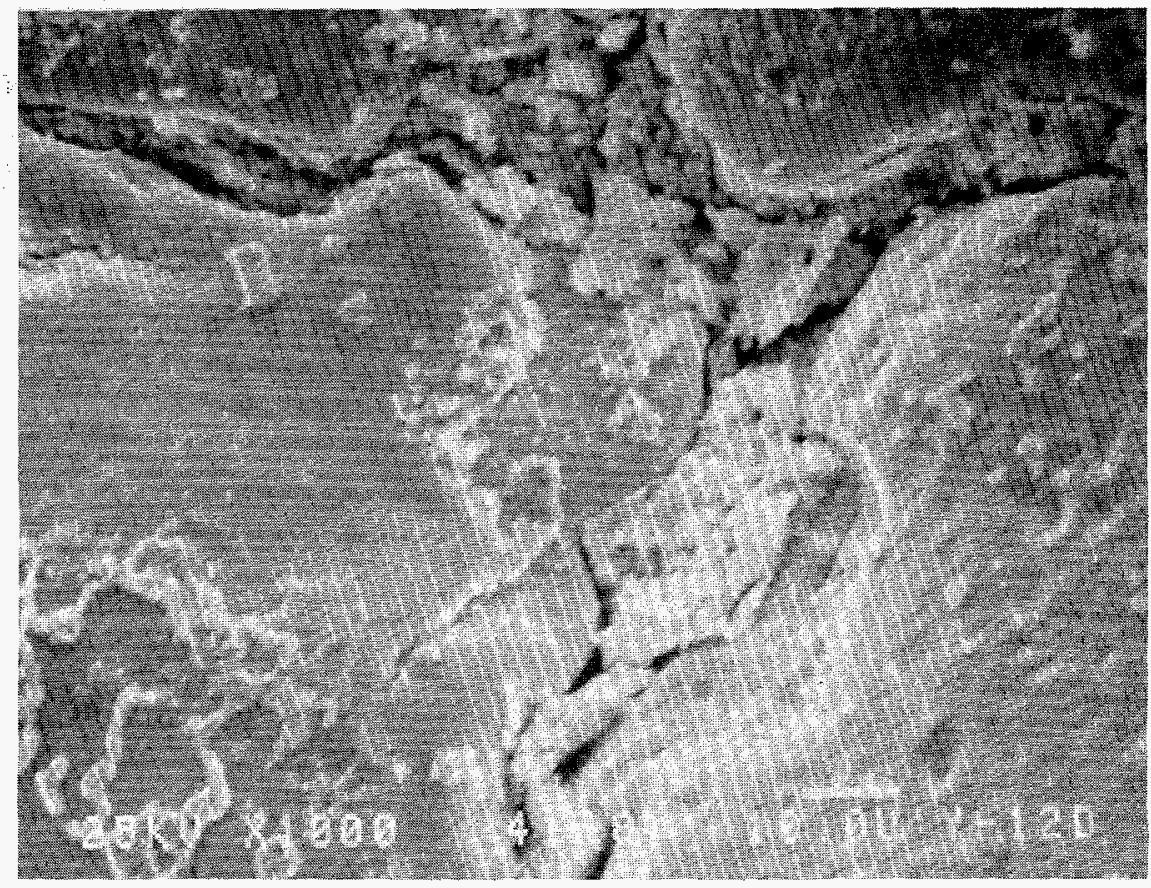

Fig. 7(b). "Mud cracks" in the residue deposited on a 200-round screw (1000X) 
areas of intergranular cracking. Changes in the microstructure also become evident in Fig. 9 in the region on the upper left side of the photograph. This region shows up as a white, crescent-shaped region in the photograph of the microstructure. At first, this region was thought to be an area that had undergone decarburization. However, micro X-ray analysis of the carbon content in the white region was similar to that of the matrix. At higher magnification, structural transformation within the white region became more evident by the absence of acicular needles, which are present in the matrix and indicative of martensite. Microhardness testing of this region revealed a range in hardness (see Fig. 10), but, more importantly, a significant increase in hardness of approximately 670 in this white region. A slight decrease in microhardness was observed in a narrow layer between the white region and the matrix.

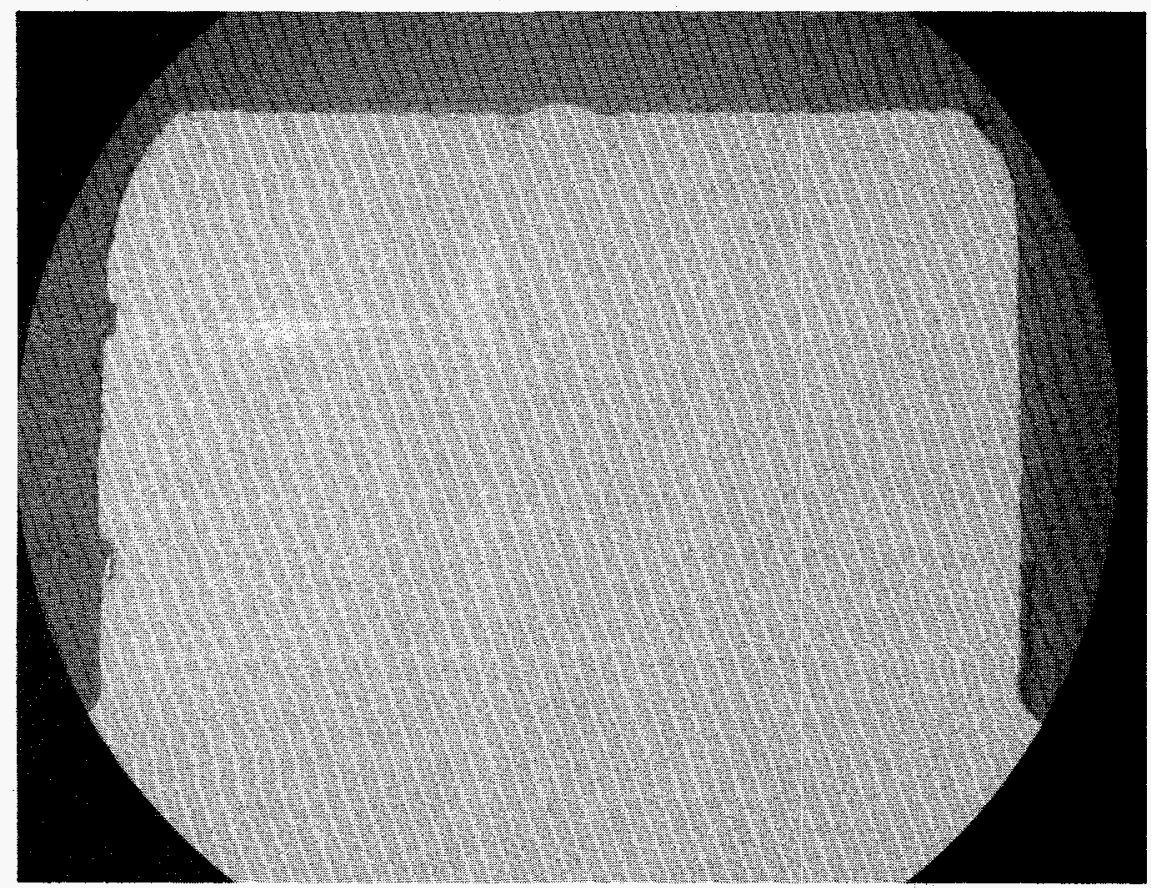

Fig. 8(a). Polished cross section of a screw after 200 rounds. Note the increase in the number of cracks along the top surface $(30 \mathrm{X})$ 


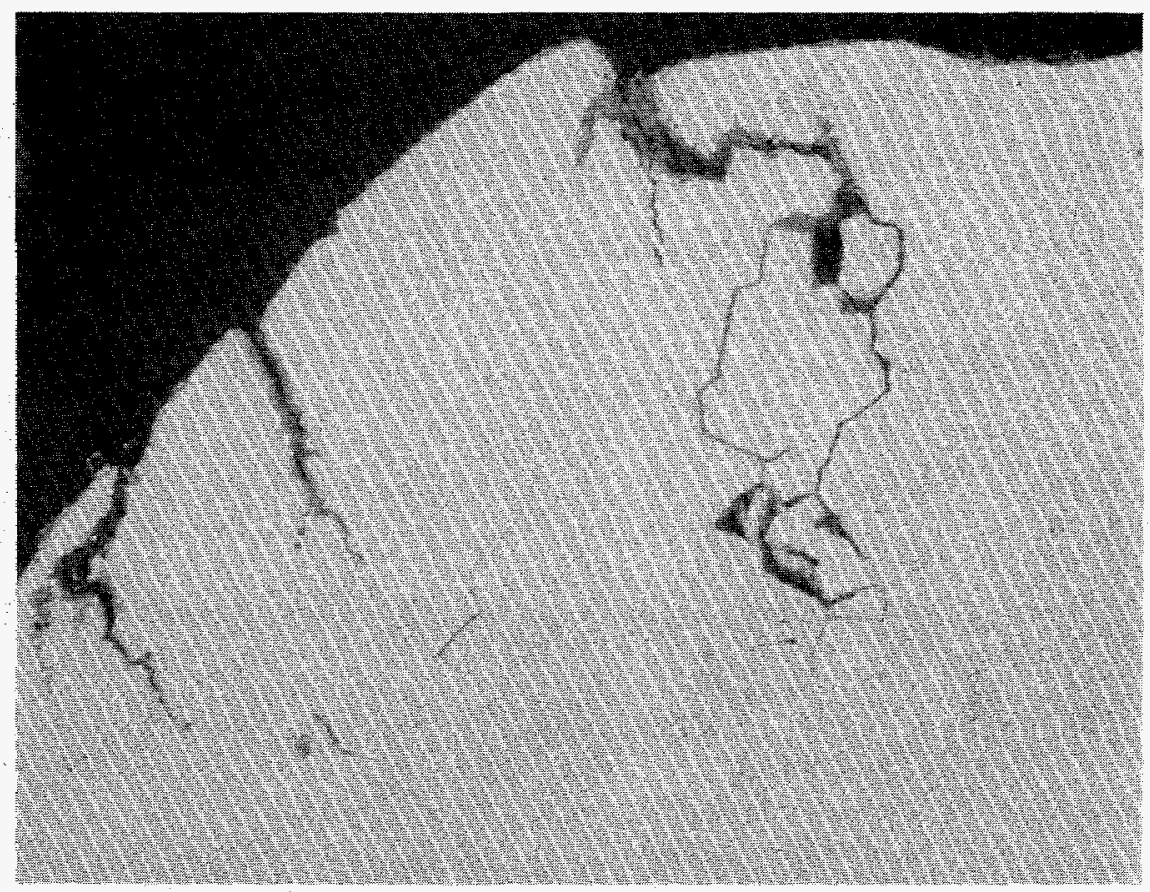

Fig. 8(b). Magnification increased for a closer look at the degree of cracking in the left upper portion of Fig. 8(a) (400X).

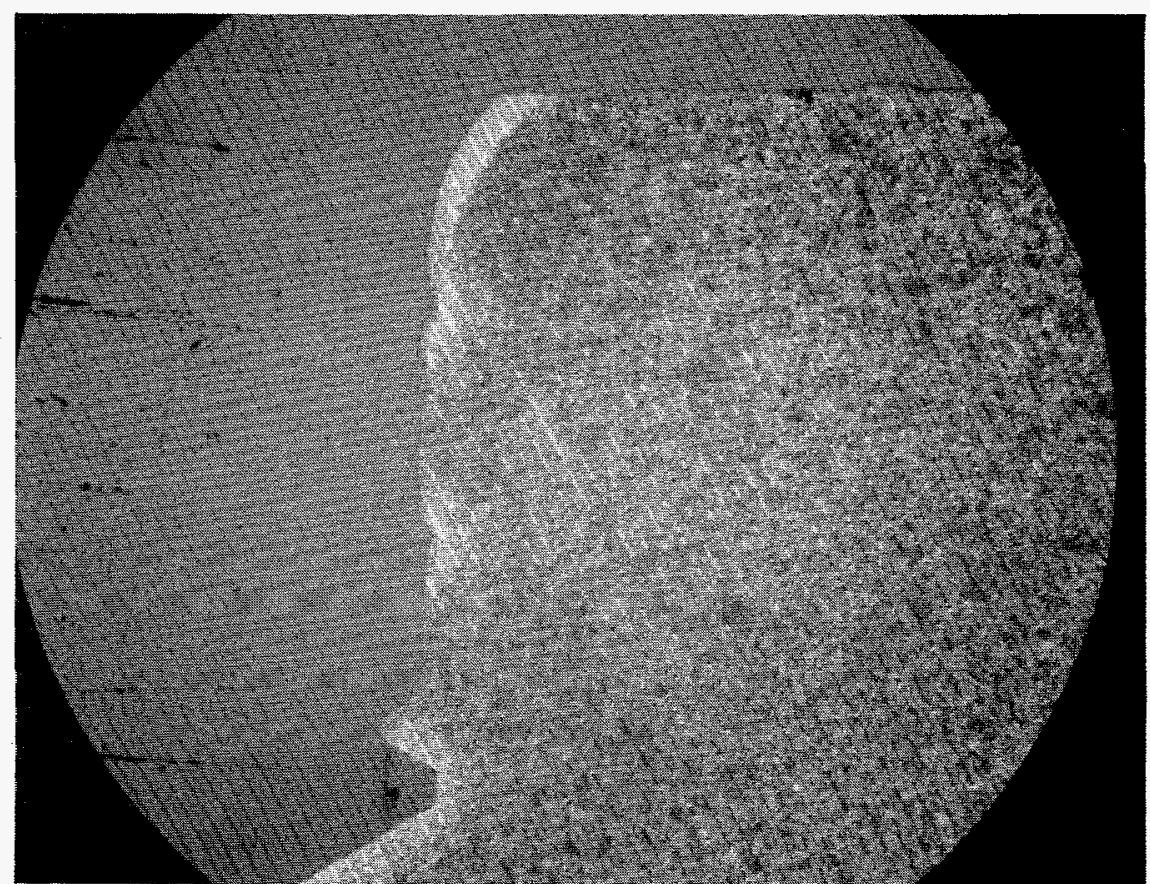

Fig. 9(a). Etched microstructure of a screw after 200 fired rounds. Note the "white layer" at the top left portion of the screw (30X). 


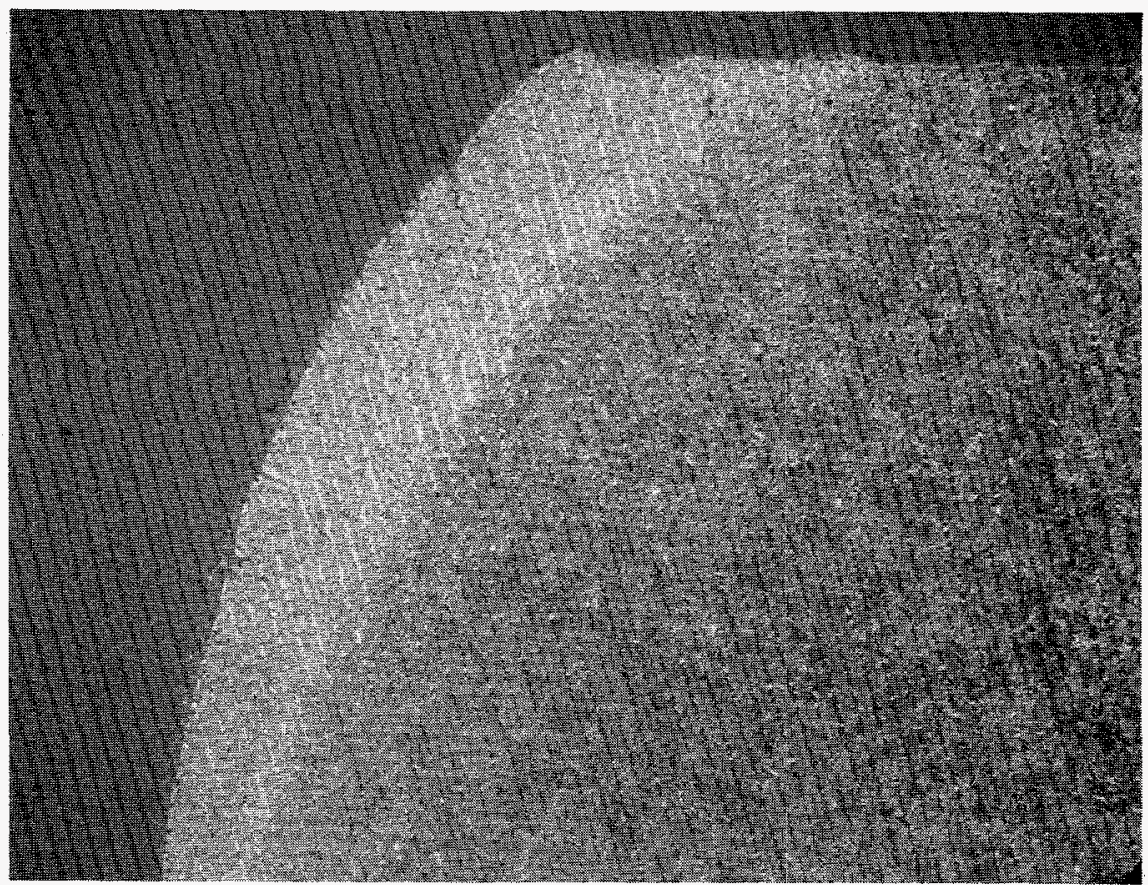

Fig. 9(b). A closer view of the white layer on the screw from 200 fired rounds (150X).

Y-GA $96-1914$

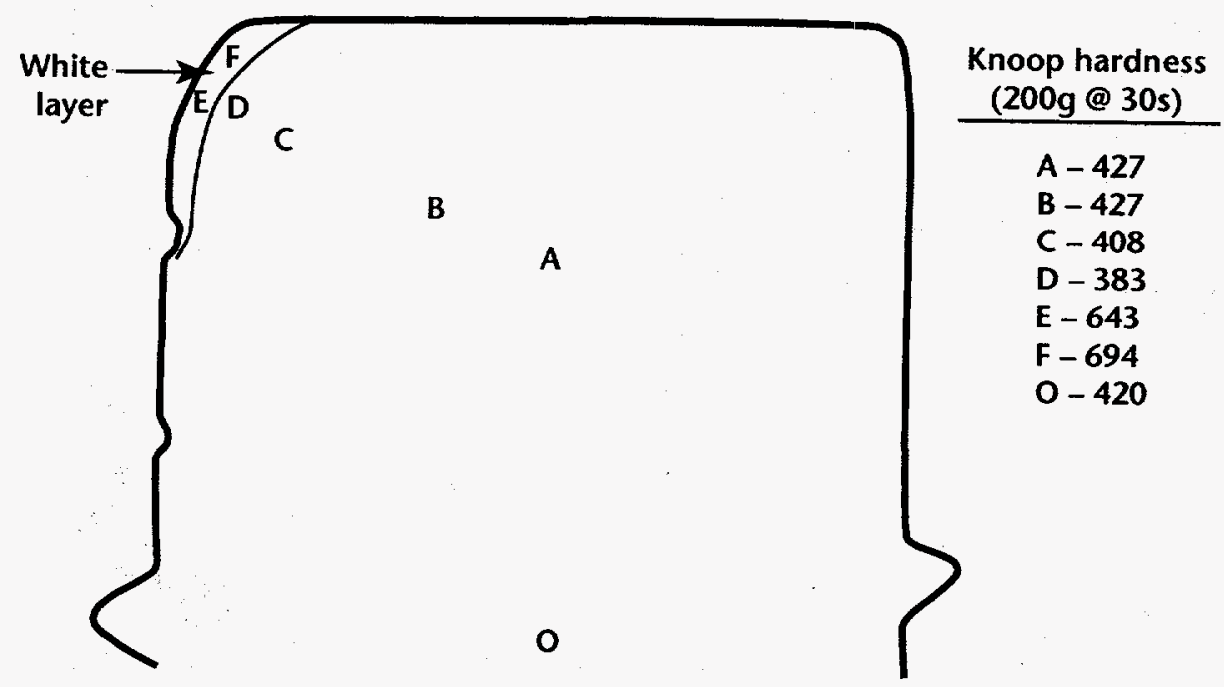

Fig. 10. Microhardness results of a screw exposed to the firing of 200 rounds. 


\section{SCREW AFTER 300 ROUNDS}

The tips of each of the two 300-round screws were heavily covered with gun powder residue and revealed large cracks on the surface, as shown in Fig. 11. Several of these cracks began to branch and propagate along the intergranular paths, as shown in Fig. 12. Changes in microstructure are more significant in these specimens as indicated by a difference in appearance marked by the presence of a zone or "white band," as seen in Fig. 13(a), in a plane between the blunt tip and the threaded portion of the screw. Microhardness values taken around the surface regions of the blunt tips of two screws exposed to 200 firings revealed a variation in hardness, as shown in Fig. 14. The residue on the surface of one of these tips was analyzed using X-ray spectra analysis, revealing several heavy elements, including lead, barium, antimony, and copper, as noted in Fig. 15.

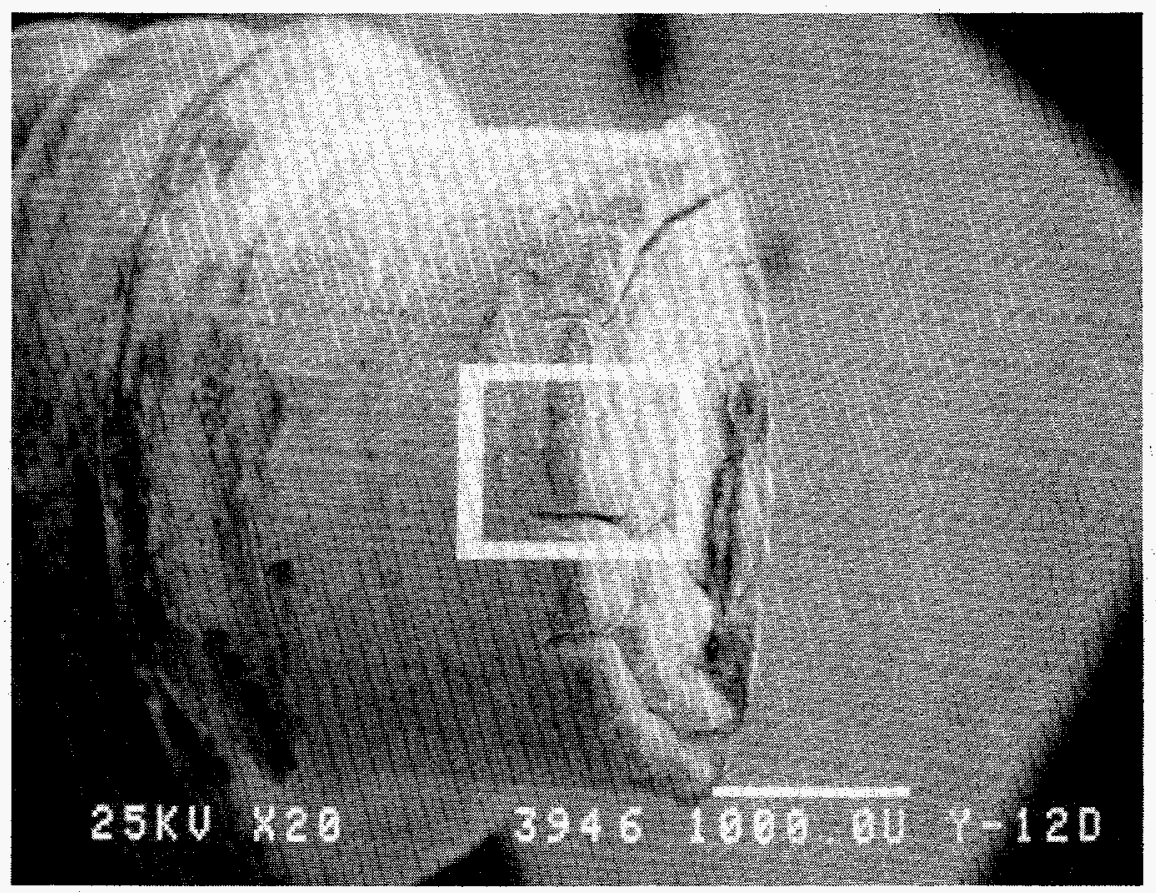

Fig. 11(a). Scanning electron microscopy image of a screw after $\mathbf{3 0 0}$ rounds. Note the enclosed box depicting the region of heavy residue and cracking. (20X) 


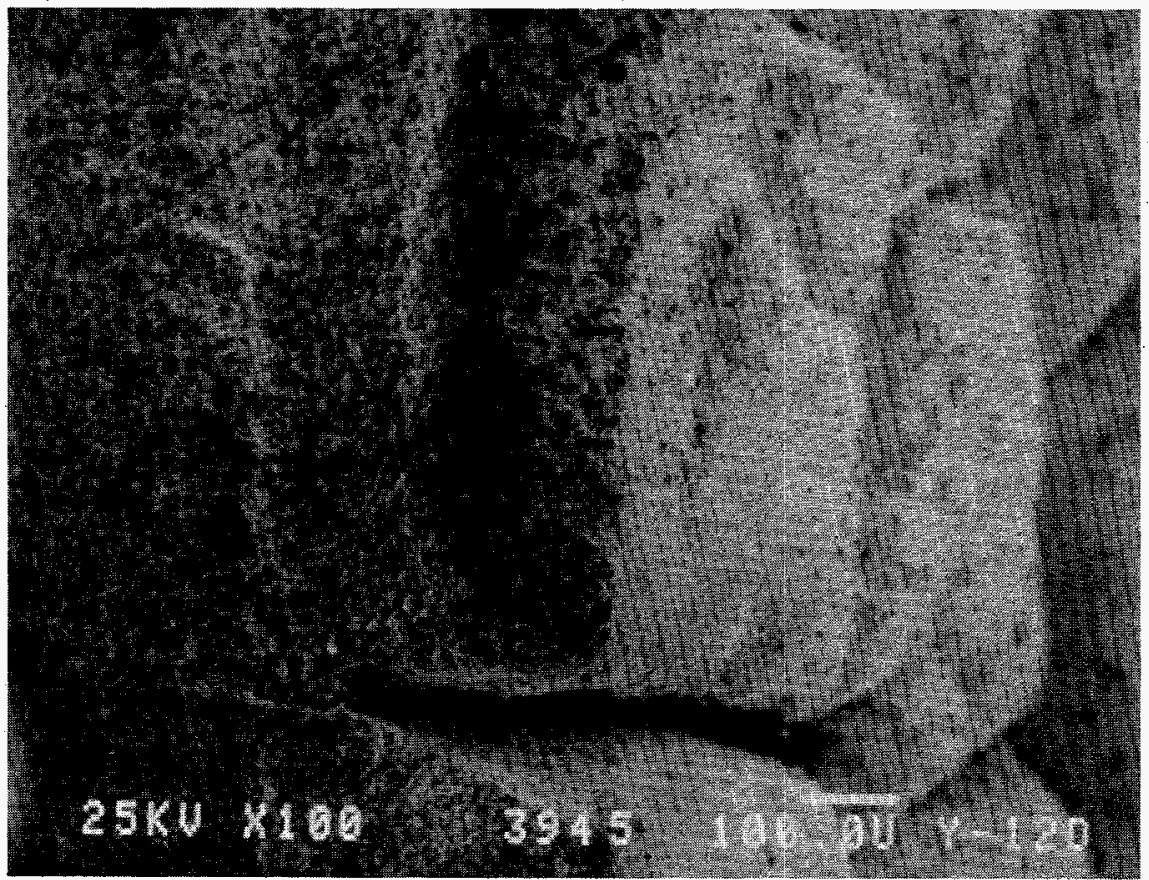

Fig. 11(b). Scanning electron microscopy image of the enhanced area from Fig. 11(a) showing cracking at higher magnification (100X).

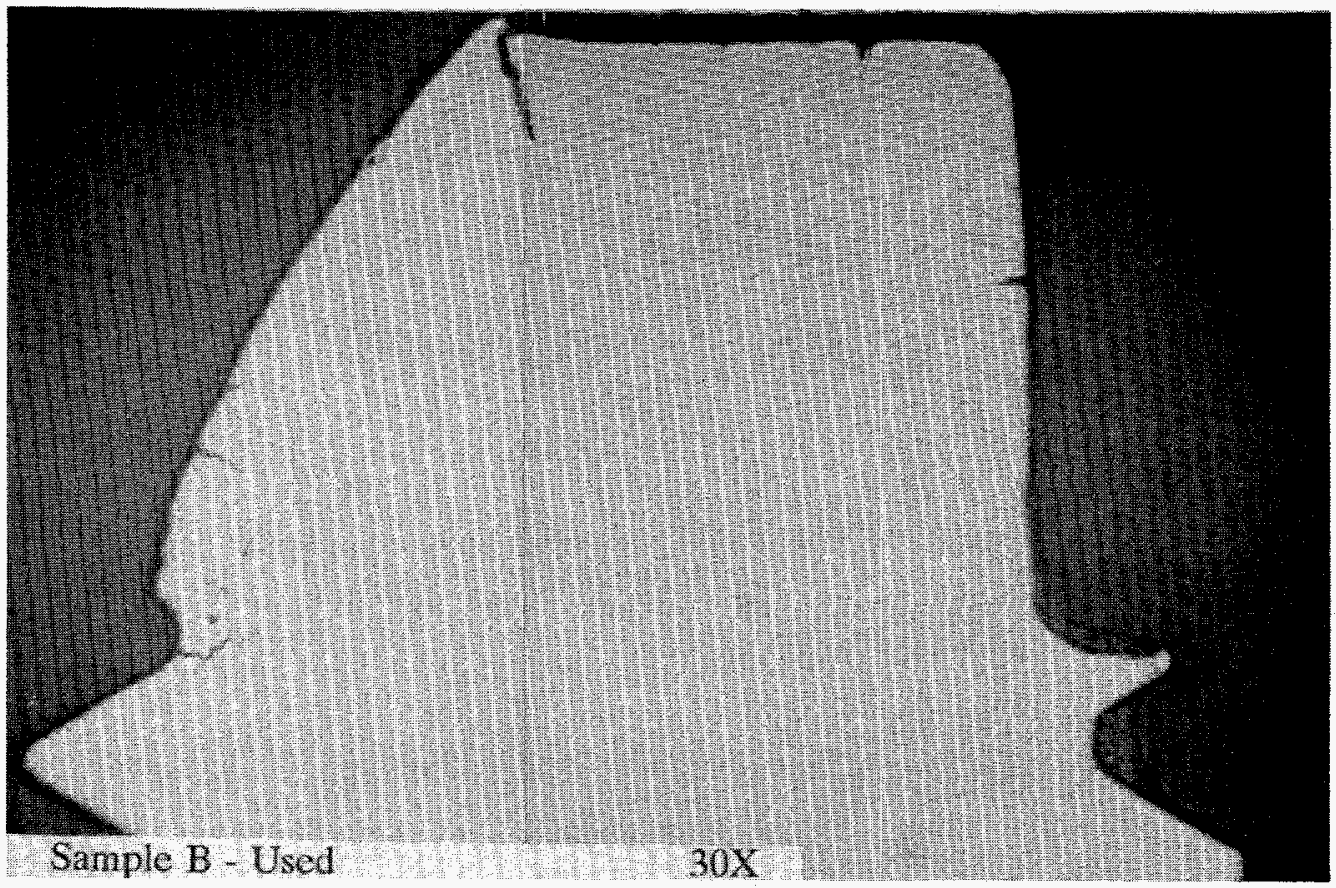

Fig. 12(a). Polished cross section of a screw after 300 rounds. Note the severity of the cracking and wear, which is predominant on the left side of the screw (30X). 


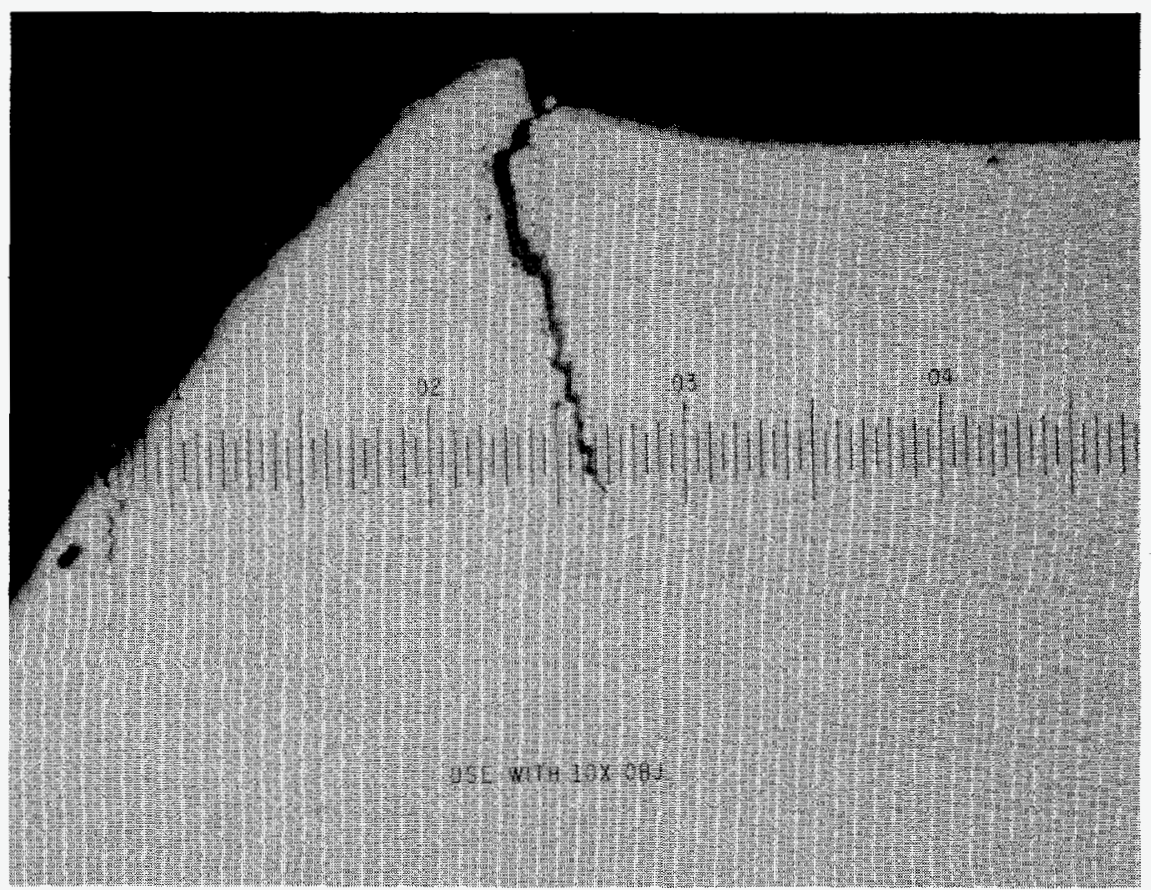

Fig. 12(b). Magnified view of Fig. 11(a), upper left corner, showing the depth of the crack (approximately 0.017 in.) and deformed metal at the crack origin $(100 \mathrm{X})$.

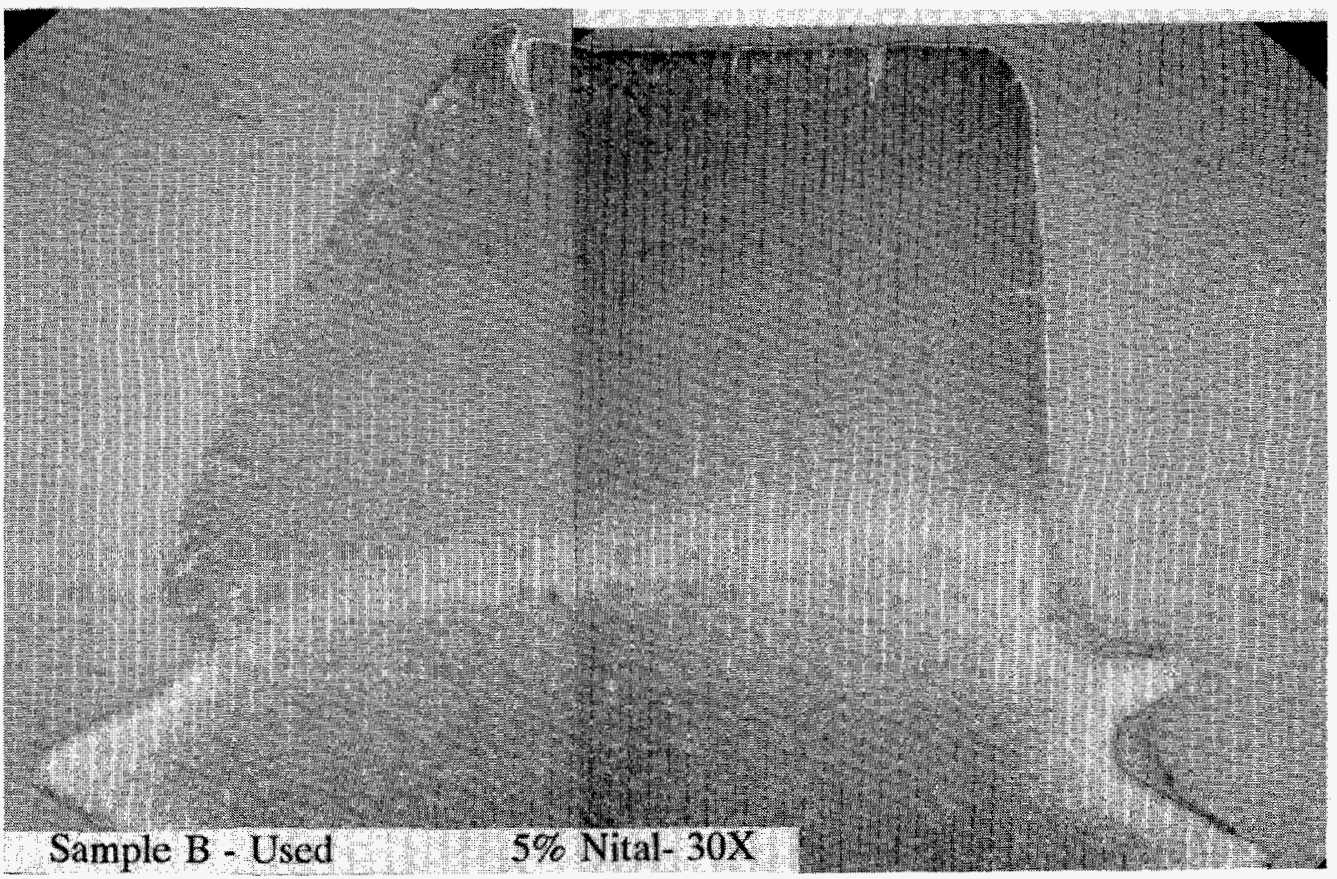

Fig. 13(a). Etched view of a screw after 300 rounds. Note the white zone or band across the screw in a plane slightly above the threaded plane and the difference in the appearance of the microstructure above and below this band. (30X) 


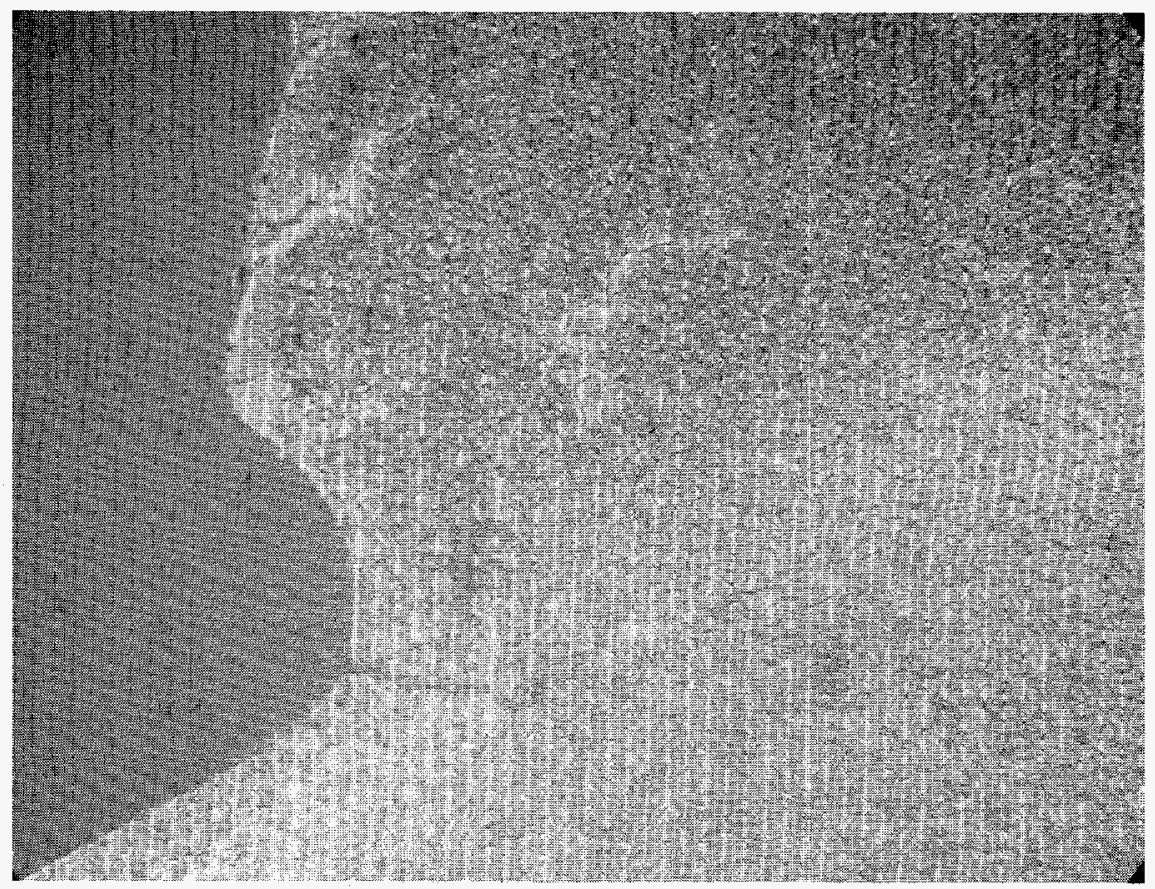

Fig. 13(b). Magnified view of the region above the top, left thread shown in the bottom left portion of Fig. 12(a). The differences in microstructure are more evident (150X).

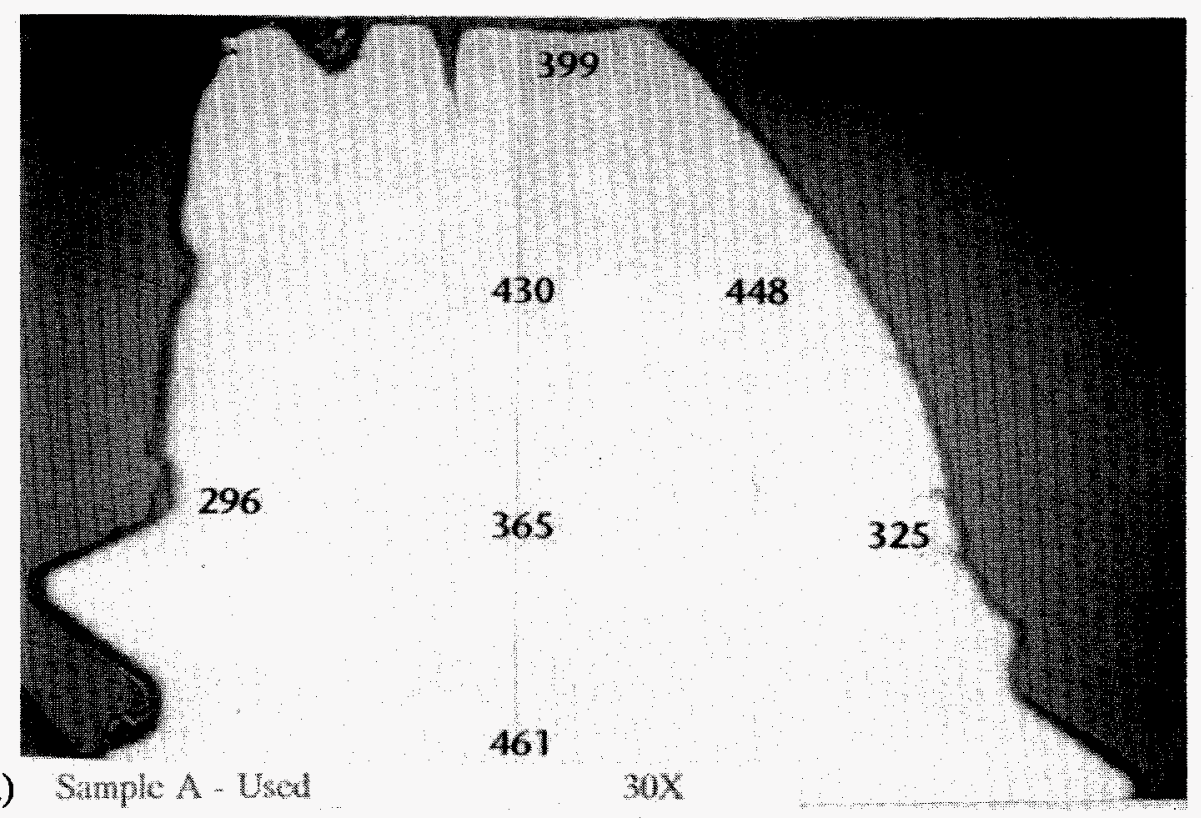

Fig. 14. Profiles of Knoop hardness tests at a 500-g load for 15 s. (a) and (b) 300-round screws, (c) new screw (30X). 

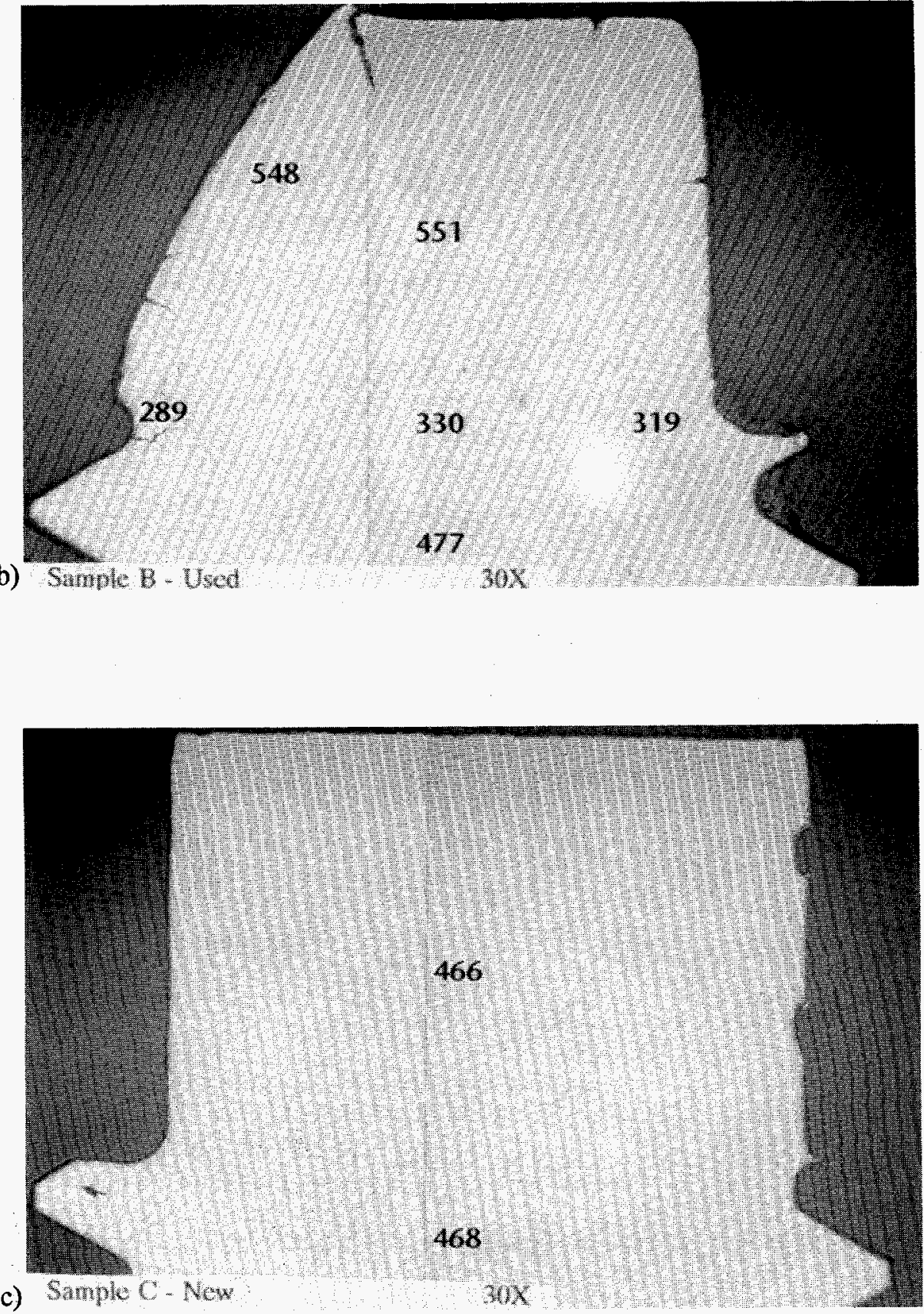

Fig. 14. Profiles of Knoop hardness tests at a 500-g load for $15 \mathrm{~s}$. (a) and (b) 300-round screws, (c) new screw (30X). 


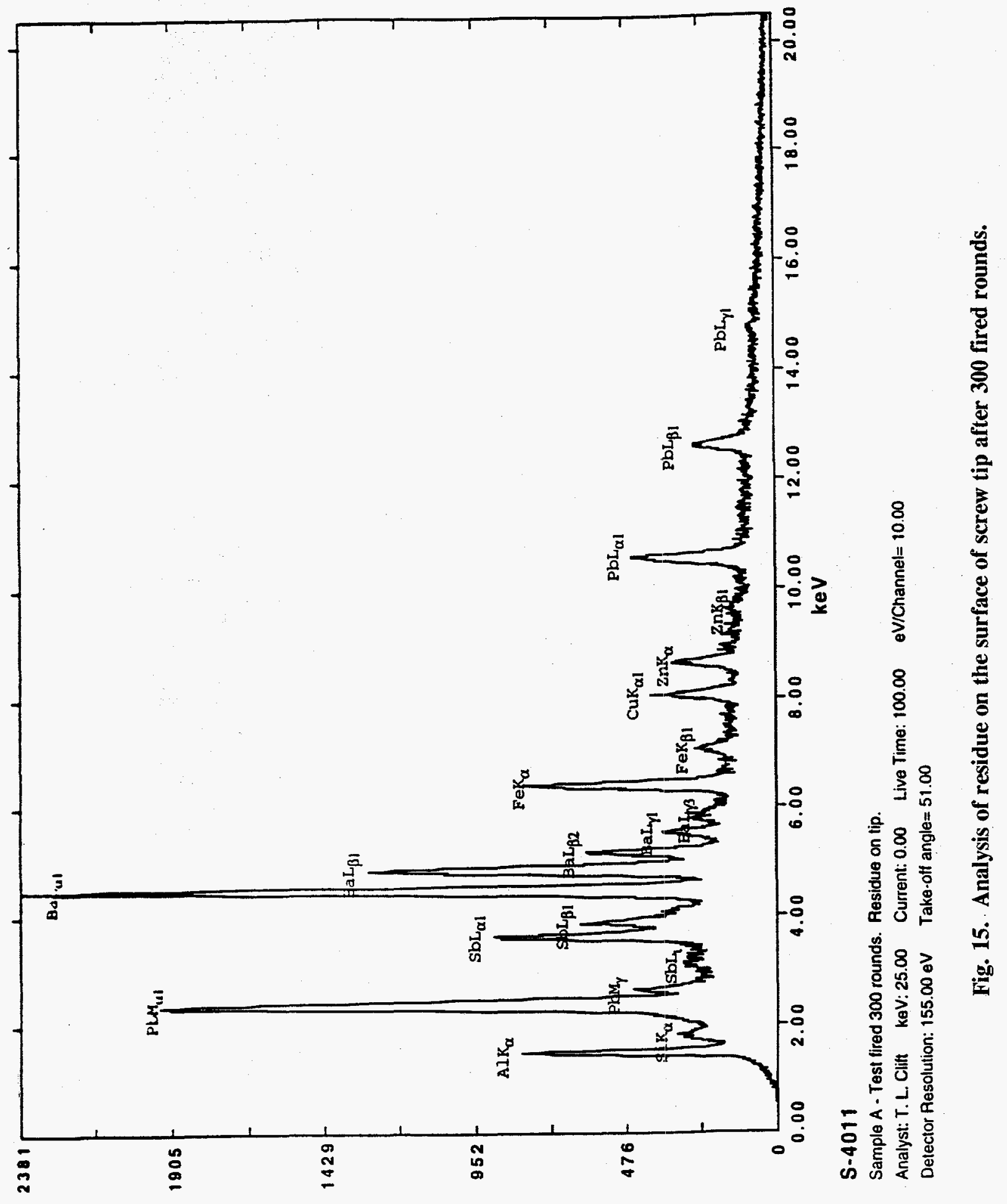




\section{CONCLUSIONS}

All of the screws exhibited some degree of cracking, which is generally undesirable when the component is expected to sustain structural loads. A crack tip acts as a notch or stress raiser that can lead to premature failure. Some of the cracks appear to initiate along a transgranular path, whereas some of the finer cracks propagate along intergranular paths with evidence of branching. The larger cracks could be caused solely by thermal shock or fatigue as a result of repeated firing. As these cracks continue to develop, gun powder residue or primer materials begin to fill in the cracks. These materials are corrosive to mild steel.

The combination of applied stresses and corrosion leads to a form of stress-corrosion cracking. The presence of nitrates in the gunpowder creates a condition that is conducive to stress-corrosion cracking in carbon steels. Even if they are present in low concentrations or as impurities, nitrates can cause stresscorrosion cracking in carbon steels at temperatures $>210^{\circ} \mathrm{F}^{1}{ }^{1}$ The general appearance of "mud" cracks on the surface of some of the screws is also indicative of stress-corrosion cracking. Another potential contributor that might explain the cause of branch cracking is associated with liquid-metal embrittlement, which occurs at elevated temperatures. ${ }^{2}$ Elements such as antimony and brass can cause liquid-metal embrittlement of steel, leading to cracking and a loss of ductility.

In addition to cracking, another condition of degradation observed in the screws that had experienced the firing of 200 to 300 rounds was the formation of a structural transformation zone, as indicated by a white band within the microstructure that is different from the other microstructures. In fact, the transformation zone starts at the surface of the screw that was in direct contact with the firing of 200 blank rounds and moves deeper into the screws that experienced the firing of 300 rounds. This transformation zone, which appears whiter or lighter than the matrix when etched, is believed to have been caused by additional heating of the blunt tip of the screw. Specifically, the heat generated by the firing of the rounds created cyclic blasts of heat that led, in effect, to a combination of undertempering and overtempering of the portion of the screw exposed in the barrel. Undertempered martensite, when etched, is very white and typically very hard and brittle, much like the white crescent-shaped region of the screw exposed to 200 rounds. Overtemperilng leads to a decrease in hardness, which was verified when microhardness tests identified a loss in hardness in the outer regions of the 300-round specimens.

Finally, as tempering or heating of the steel increases, the carbide particles become progressively larger and fewer in number, leading to a further decrease in hardness. ${ }^{3}$ Consequently, an "overtempering" effect occurs, and the properties of the material change. In the presence of nitrates, the carbon-rich areas act as cathodes, causing a dissolution of ferrite and selective cracking of an intergranular nature. ${ }^{3}$ Strong carbide-forming elements-such as chromium, tantalum, and titanium-are generally helpful in resisting stress-corrosion cracking. 



\section{RECOMMENDATIONS}

Based on the results of this investigation, the authors cannot recommend that the use of these screws be discontinued because of the presence of cracking observed after only 100 rounds. The presence of a crack is undesirable in just about any component that is expected to sustain loading and could cause premature failure or fragments that become potential projectiles. Our recommendation would be that a new material be substituted for the existing material or that the current material be processed in a manner that provides more resistance to heat and/or corrosion of the material. For example, a steel or stainless steel with more alloying elements, such as nickel or chromium, would offer improvements in corrosion resistance and strength. An even better alternative would be a nickel-based alloy. Hard facing or nitriding of the current material may provide some wear and erosion benefits. Finally, cleaning of the screws after firing might eliminate the buildup of gun powder residue and the corrosive attack on the screw, thus leading to longer service life. 



\section{REFERENCES}

1. "Failure Analysis and Prevention," Metals Handbook, 8th ed., vol. 10, p. 210, American Society of Metals, Metals Park, Ohio, 1975.

2. "Failure Analysis and Prevention," Metals Handbook, 8th ed., vol. 10, pp. 81, 228-229, American Society of Metals, Metals Park, Ohio, 1975.

3. "Heat Treating, Cleaning, and Finishing," Metals Handbook, 8th ed., vol. 2, p. 47, American Society of Metals, Metals Park, Ohio, 1964. 